Review

\title{
Engineering Performance of Concrete Incorporated with Recycled High-Density Polyethylene (HDPE)-A Systematic Review
}

\author{
Sonali Abeysinghe ${ }^{1,2}$, Chamila Gunasekara ${ }^{1, *} \mathbb{1}$, Chaminda Bandara ${ }^{2} \mathbb{D}$, Kate Nguyen ${ }^{1}$, Ranjith Dissanayake ${ }^{2}$ \\ and Priyan Mendis ${ }^{3}$ \\ 1 School of Engineering, RMIT University, Melbourne, VIC 3000, Australia; \\ S3871542@student.rmit.edu.au (S.A.); kate.nguyen@rmit.edu.au (K.N.) \\ 2 Faculty of Engineering, University of Peradeniya, Peradeniya 20400, Sri Lanka; \\ csbandara@eng.pdn.ac.lk (C.B.); ranjith@fulbrightmail.org (R.D.) \\ 3 School of Engineering, University of Melbourne, Grattan Street, Parkville, VIC 3010, Australia; \\ pamendis@unimelb.edu.au \\ * Correspondence: chamila.gunasekara@rmit.edu.au; Tel.: +61-3-9925-1709
}

\section{check for}

updates

Citation: Abeysinghe, S.;

Gunasekara, C.; Bandara, C.; Nguyen,

K.; Dissanayake, R.; Mendis, P.

Engineering Performance of Concrete

Incorporated with Recycled

High-Density Polyethylene

(HDPE) - A Systematic Review.

Polymers 2021, 13, 1885. https://

doi.org/10.3390/polym13111885

Academic Editor: Miguel Ángel

López Manchado

Received: 25 May 2021

Accepted: 4 June 2021

Published: 6 June 2021

Publisher's Note: MDPI stays neutral with regard to jurisdictional claims in published maps and institutional affiliations.

Copyright: (c) 2021 by the authors. Licensee MDPI, Basel, Switzerland This article is an open access article distributed under the terms and conditions of the Creative Commons Attribution (CC BY) license (https:// creativecommons.org/licenses/by/ $4.0 /)$

\begin{abstract}
Incorporating recycled plastic waste in concrete manufacturing is one of the most ecologically and economically sustainable solutions for the rapid trends of annual plastic disposal and natural resource depletion worldwide. This paper comprehensively reviews the literature on engineering performance of recycled high-density polyethylene (HDPE) incorporated in concrete in the forms of aggregates or fiber or cementitious material. Optimum 28-days' compressive and flexural strength of HDPE fine aggregate concrete is observed at HDPE-10 and splitting tensile strength at HDPE-5 whereas for HDPE coarse aggregate concrete, within the range of $10 \%$ to $15 \%$ of HDPE incorporation and at HDPE-15, respectively. Similarly, 28-days' flexural and splitting tensile strength of HDPE fiber reinforced concrete is increased to an optimum of $4.9 \mathrm{MPa}$ at HDPE-3 and 4.4 MPa at HDPE-3.5, respectively, and higher than the standard/plain concrete matrix (HDPE-0) in all HDPE inclusion levels. Hydrophobicity, smooth surface texture and non-reactivity of HDPE has resulted in weaker bonds between concrete matrix and HDPE and thereby reducing both mechanical and durability performances of HDPE concrete with the increase of HDPE. Overall, this is the first ever review to present and analyze the current state of the mechanical and durability performance of recycled HDPE as a sustainable construction material, hence, advancing the research into better performance and successful applications of HDPE concrete.
\end{abstract}

Keywords: sustainability; recycled plastic; high-density polyethylene (HDPE); concrete; construction material

\section{Introduction}

About 2.01 billion tons of Municipal Solid Waste (MSW) is generated annually worldwide, and one third of MSW is openly dumped without managing in an environmentallyfriendly manner [1]. Around $40 \%$ of MSW is discharged directly to landfills, $19 \%$ of it is recovered through recycling or composting and another $11 \%$ of it is incinerated [1]. With the rapid trends of urbanization, it has been predicted that 3.40 billion tons of MSW will be generated by 2050 [1]. About 12\% of MSW generated are plastics, which is approximately 24.14 million tons [1]. The plastic industry began in the early 1900s in the USA [2]. During the period of 1950 to $2015,8.3$ billion tons of plastics were manufactured worldwide and 6.3 billion tons of them were discharged as waste [3]. Only $9 \%$ of plastic waste had been recycled, $12 \%$ were incinerated and the majority of $79 \%$ was discharged into landfills or openly dumped [3]. China ranks at the top in plastic manufacturing followed by Europe which accounts for 30\% and 19\%, respectively. Furthermore, China tops even in plastic consumption followed by Western Europe which is around $20 \%$ and $18 \%$, respectively [4]. 
Plastic is one of the vastly discharged wastes to the environment which has adversely affected the wildlife, their habitats, and humans continuously over the past few decades. This emphasizes that it is high time to rethink the necessity of plastic recycling and reusing.

Today, more than 30 types of primary plastics and over thousands of different secondary plastics can be found, produced by using different combinations and proportions of primary plastics [5]. Plastics can also be categorized based on many aspects as illustrated in Figure $1[4,5]$. Different plastics have different characteristics such as mechanical properties, durability resistances and diverse applications based on their compositions and chemical structures. The most commonly manufactured and applied plastics in the world are polyethylene (PE), polypropylene (PP), polyvinyl chloride (PVC), polyethylene terephthalate (PET) and polystyrene (PS) which represents $69 \%$ of the global plastic consumption [4]. Out of global plastic production, the polypropylene (PP) and low-density polyethylene (LDPE) account for $17 \%$ and $16 \%$, respectively, followed by high-density polyethylene (HDPE) (13\%) and polyphthalamide (PP\&A) (13\%). In addition, additives used in plastic products' manufacturing also have a significant share in global plastic production (6\%) [4]. Moreover, the use of combustible claddings in high-rises significantly increase the risk of fire spread via the external façades [6]. Urgent work on the removal of polyethylene-based claddings is necessary to ensure the safety of the occupants and buildings but also accounts for a substantial amount of PE sent to landfill.

Concrete is ranked as the topmost man-made resource utilized in the construction industry worldwide. The global aggregate requirement for concrete production accounts for about 4.5 billion tons per year which alarms the necessity of finding alternative aggregate sources required for increasing trends of concrete production [7]. Incorporating recycled plastic waste in concrete production is a sustainable approach for both disposing of plastic waste and aggregate scarcity, due to its economic and ecological advantages. Concrete composites replace various types of recycled plastics in the forms of aggregate, binder, filler or fiber reinforcement in different proportions where concrete properties are optimized [8]. PP, PET and HDPE are the most used plastics in the construction industry. However, the application and research studies on HDPE being used with concrete is very minimal compared with PP and PET.

HDPE is a thermoplastic synthetic polymer in the subset of the PE macro plastic group. PE polymer consists of neverlasting hydrocarbon chains where each carbon molecule is bound to another two carbon molecules and two hydrogen molecules. HDPE has minimal branches in its polymer chain which results to pack liner molecular chains together regularly during crystallization. As a result, semi-crystalline HDPE polymers become much more dense, rigid, and ductile with a comparatively strong bending strength between 20 to $45 \mathrm{MPa}$ due to the regular packing of polymer chains [3-5]. HDPE also has a low density between 950 to $970 \mathrm{~kg} / \mathrm{m} 3$, a better flexibility, and a high tensile strength between 20 to $32 \mathrm{MPa}$ [3-5]. Further, HDPE is a chemically inert [3-5] material and its melting point is at $130^{\circ} \mathrm{C}$ while ignition temperature is at $487^{\circ} \mathrm{C}$ [9]. 


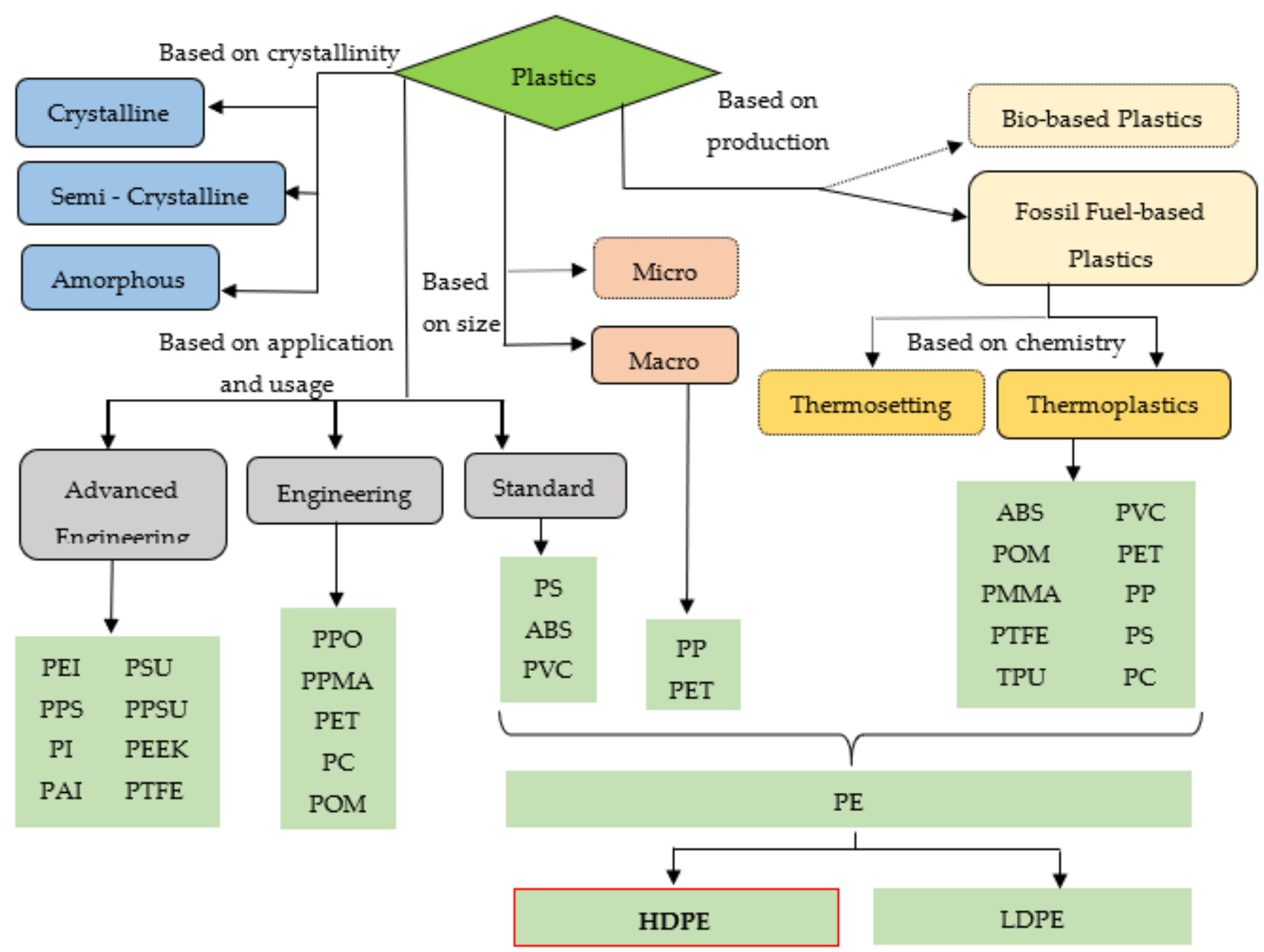

PEI- Polyetherimide; PPS- Polyphenylene Sulfide, PI- Polyimid, PAI- Polyamide-imide, PBI- Polybenzimidazole, PSUPolysulfone, PPSU-Polyphenylsulfcne, PEEK-Polyetheretherketone, PTFE- Fluoropolymer/ Teflon, PPO-Polyphenylene Oxide, PPMA- Polymethyl Methacrylate, PET- Polyethylene Terephthalate, PC- Polycarbanate, POM- Polyoxymethylene, PAPolyamide/ Nylon, PS- Polystyrene, PVC- Polyvinyl Chloride, PP- Polypropylene, ABS-Acrylonitrile+ Butadiene+ Styrene, PMMA- Acrylics / Polymethyl-methacrylate, TPU- Thermoplastic polyurethane, PE- Polyethelene, HDPE- High Density Polyethelene, LDPE- Low Density Polyethelene

Figure 1. Plastic categorization.

\section{Significance of the Review}

HDPE is the third most applied plastic type in construction preceded by PE and PET. However, a little research is reported in concrete incorporated with HDPE as a construction material, Figure 2. Moreover, there is no systematic review which was conducted by discussing existing research findings of HDPE concrete. Hence, this comprehensive review will provide the clear insight and in-depth analysis of the existing HDPE concrete performance, prevailing research gaps and future research improvements required. 


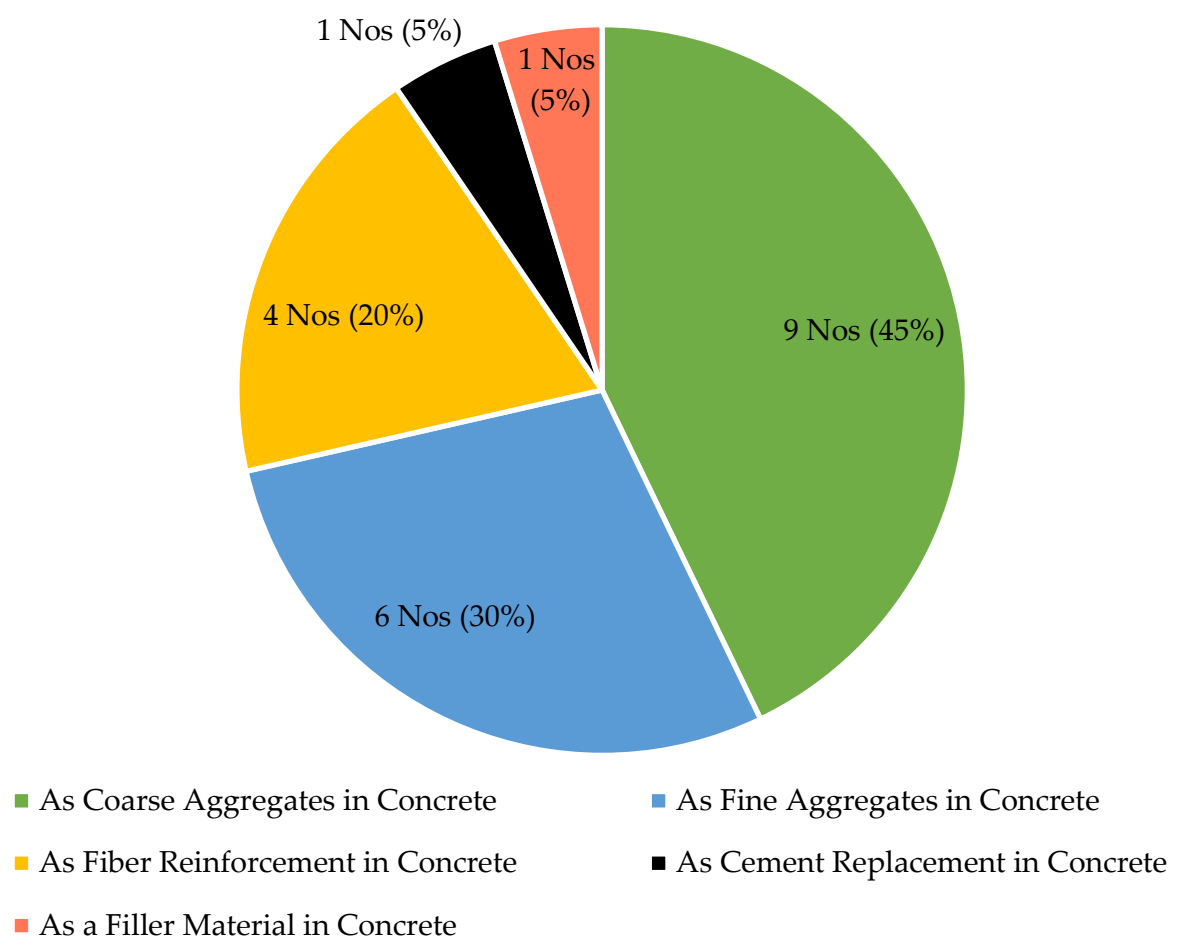

Figure 2. Use of HDPE as a construction material in concrete.

\section{Use of HDPE as an Aggregate in Concrete}

\subsection{Mechanical Properties of HDPE Fine Aggregate Concrete}

Throughout the paper, HDPE incorporated concrete is denoted in an abbreviation form, such as $10 \%$ of HDPE inclusion as HDPE- 10 and 100\% of HDPE inclusion as HDPE100, etc. Tables 1 and 2 summarizes the mechanical performances of HDPE fine aggregate concrete. It was observed that the slump (workability) is decreased from $70 \mathrm{~mm}$ to $30 \mathrm{~mm}$ when HDPE is increased from $5 \%$ to $15 \%$ while keeping the $\mathrm{w} / \mathrm{c}$ ratio a constant of 0.42 [10]. In another experiment, a constant slump of $90 \mathrm{~mm}$ is observed with the increase of $\mathrm{w} / \mathrm{c}$ ratio as 0.45 for HDPE-0, 0.50 for HDPE-25 and HDPE-50, 0.55 for HDPE-75 and 0.6 for HDPE-100 [11]. These conditions have resulted in a decrease in the compressive strength by $40.2 \%$ when HDPE is increased from $0 \%$ to $50 \%$ and by $22.3 \%$ when HDPE is increased from $50 \%$ to $100 \%$ [11]. A decreasing trend in the compressive strength of HDPE fine aggregate concrete with the increase of HDPE percentage was observed. As illustrated in Figure 3a, the 28-days' compressive strength varied between $27.5 \mathrm{MPa}$ to $42 \mathrm{MPa}$ when HDPE is added from $0 \%$ to $20 \%[10,12,13]$. Shanmugapriya and Santhi [12] observed a 3 MPa drop in compressive strength when HDPE is increased from $0 \%$ to $5 \%$. Then the optimum compressive strength of $35 \mathrm{MPa}$ was recorded at HDPE-10 [12]. Galupino et al. [13] have also observed the optimum compressive strength of 38.6 MPa at HDPE-10. Biswas [10] has obtained $35 \mathrm{MPa}$ of compressive strength at HDPE- 5 concrete but decreased by $19.3 \%$ when HDPE increased to $12.5 \%$. Badache et al. [14] have observed a decreasing trend in 28 -days' compressive strength with a drop of $52.4 \%$ and $57.8 \%$ when HDPE is increased from $0 \%$ to $50 \%$ and $50 \%$ to $100 \%$, respectively.

The 28-days' splitting tensile strength also shows a decreasing trend with the increase of HDPE content from $0 \%$ to $15 \%$, Figure $3 \mathrm{~b}$. The HDPE- 5 concrete shows the highest splitting tensile strength, $3.45 \mathrm{MPa}$, which is a $31.25 \%$ increase than the standard concrete of HDPE-0 [12]. However, a drop of $18.8 \%$ is observed with the increase of HDPE from $5 \%$ to $15 \%$ [12]. In another study, it was observed a $8.7 \%$ and $27.9 \%$ of splitting tensile strength drop when HDPE is added from $0 \%$ to $5 \%$ and from $5 \%$ to $7.5 \%$, respectively [10]. There was a tensile strength gain of $26.8 \%$ when HDPE is increased from $7.5 \%$ to $10 \%$, however, a drop of $23.8 \%$ was noted when HDPE is increased from $10 \%$ to $15 \%$ [10]. 

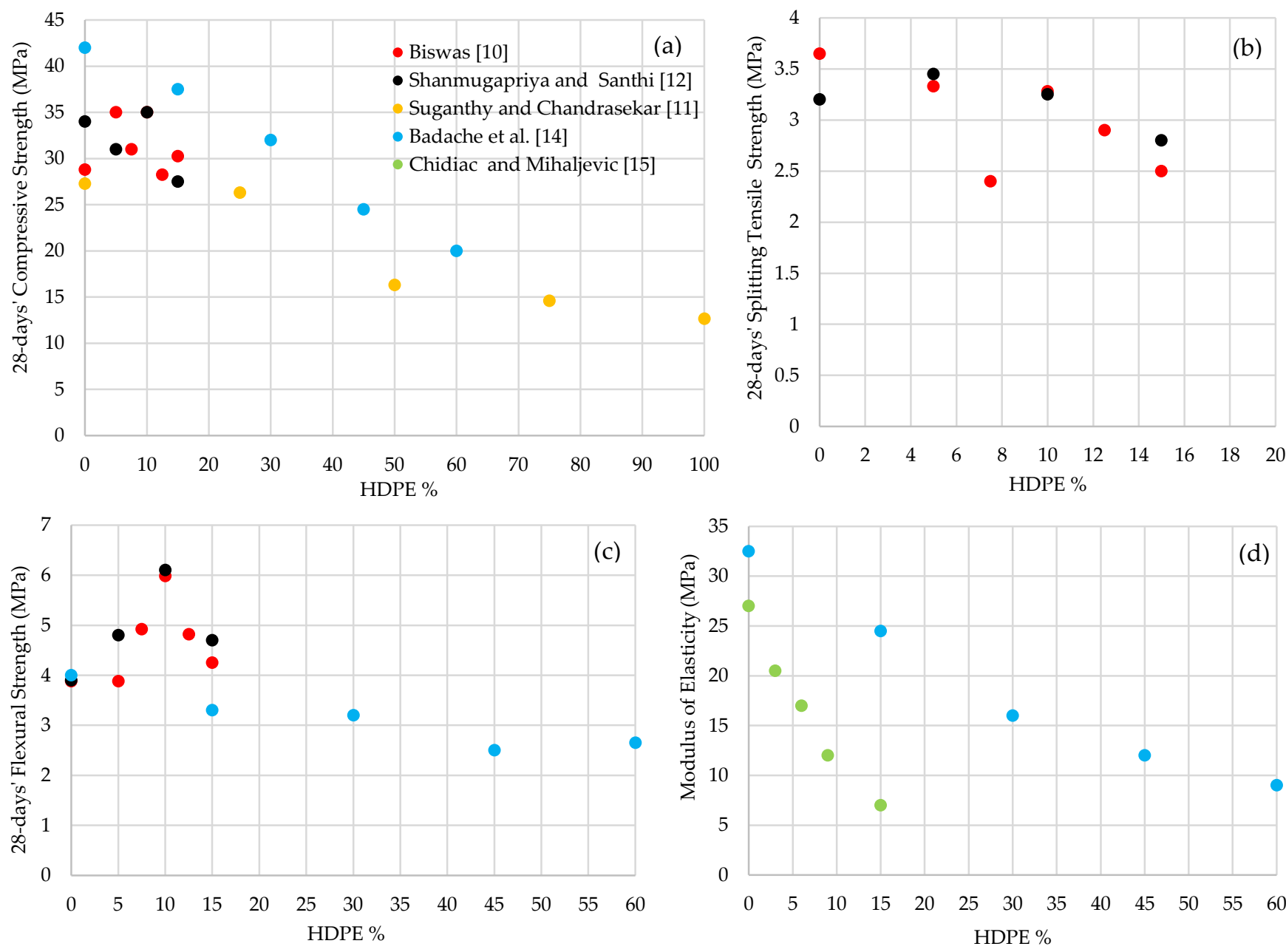

Figure 3. 28-days' (a) Compressive strength; (b) Splitting tensile strength; (c) Flexural strength and (d) Modulus of elasticity variation of HDPE fine aggregate concrete.

Similar to compressive and splitting tensile strengths, the flexural strength also decreases with the increases of HDPE fine aggregate percentage, Figure 3c. It is interesting to note that the flexural strength of concrete incorporated with HDPE up to $15 \%$ was higher than the standard concrete $[10,12]$. The flexural strength has increased by $56.4 \%$ with the increase of HDPE from $0 \%$ to $10 \%$ and obtained the optimum flexural strength of $6.1 \mathrm{MPa}$ at HDPE-10 [12]. Then, a slight strength drop of 1.4 MPa was observed at HDPE-15 [12]. A similar flexural strength development was observed by Biswas et al. [10] when HDPE is increased from $0 \%$ to $15 \%$. There was no change in flexural strength in HDPE- 0 and HDPE- 5 concretes, and then a $54.1 \%$ strength gain was noted with the increase of HDPE from $5 \%$ to $10 \%$ and obtained optimum flexural strength of $5.98 \mathrm{MPa}$ at HDPE-10 [10]. A drop of $28.9 \%$ was observed, when HDPE is added from $10 \%$ to $15 \%$ [10].

The modulus of elasticity is decreased with the increase of HDPE percentage, Table 2. According to Figure $3 d$, there was a considerable elasticity modulus decrease, $74 \%$, when HDPE content increases up to $15 \%[14,15]$. It is observed that the density of the HDPE fine aggregate concrete is decreased with the increase of recycled HDPE content, Table 2. The density of HDPE fine aggregate concrete has varied from $2165 \mathrm{~kg} / \mathrm{m}^{3}$ to $1825 \mathrm{~kg} / \mathrm{m}^{3}$, when HDPE increases from $0 \%$ to $15 \%$ [15]. Badache et al. [14] have observed a $20 \%$ density reduction with the increase of HDPE from $0 \%$ to $60 \%$ and obtained a density of $1760 \mathrm{~kg} / \mathrm{m} 3$ at HDPE-60. 
Table 1. Mix design and compressive strength properties of HDPE fine aggregate concrete.

\begin{tabular}{|c|c|c|c|c|c|c|c|c|c|c|c|c|c|c|c|c|c|}
\hline \multirow{3}{*}{ Reference } & \multicolumn{9}{|c|}{ Mix Design } & \multirow{2}{*}{\multicolumn{8}{|c|}{$\begin{array}{c}\text { Mechanical Properties } \\
\text { Compressive Strength (MPa) }\end{array}$}} \\
\hline & \multirow{2}{*}{$\begin{array}{l}\text { Cement } \\
\left(\mathrm{kg} / \mathrm{m}^{3}\right)\end{array}$} & \multirow[b]{2}{*}{$\underset{\%}{\text { HDPE }}$} & \multirow[b]{2}{*}{$\underset{\%}{\text { Sand }}$} & \multirow{2}{*}{$\underset{\left(\mathrm{kg} / \mathrm{m}^{3}\right)}{\mathrm{HDPE}}$} & \multirow[b]{2}{*}{$\underset{\left(\mathrm{kg} / \mathrm{m}^{3}\right)}{\text { Sand }}$} & \multirow{2}{*}{$\begin{array}{l}\text { Coarse Aggregates } \\
\left(\mathrm{kg} / \mathrm{m}^{3}\right)\end{array}$} & \multirow[b]{2}{*}{$\underset{\left(\mathrm{kg} / \mathrm{m}^{3}\right)}{\text { Water }}$} & \multirow[b]{2}{*}{$\begin{array}{l}\text { W/C } \\
\text { Ratio }\end{array}$} & \multirow{2}{*}{$\begin{array}{c}\text { Admixtures/ } \\
\underset{(\mathbf{w} \%)}{\text { Superplasticizer }}\end{array}$} & & & & & & & & \\
\hline & & & & & & & & & & $\begin{array}{c}3 \\
\text { days }\end{array}$ & $\begin{array}{c}7 \\
\text { days }\end{array}$ & $\begin{array}{c}14 \\
\text { days }\end{array}$ & $\begin{array}{c}28 \\
\text { days }\end{array}$ & $\begin{array}{c}90 \\
\text { days }\end{array}$ & $\begin{array}{c}120 \\
\text { days }\end{array}$ & $\begin{array}{c}160 \\
\text { days }\end{array}$ & $\begin{array}{c}180 \\
\text { days }\end{array}$ \\
\hline [10] & 315 & 0 & 100 & 0 & 892.2 & 1285.5 & 132.3 & 0.42 & - & - & 17.77 & 23.09 & 28.8 & - & - & - & - \\
\hline [13] & - & 0 & 100 & - & - & - & - & - & - & - & 29.65 & 33.49 & 34.2 & - & 34.38 & - & - \\
\hline [12] & 320 & 0 & 100 & - & 848.6 & 1286.5 & 134.4 & 0.42 & - & - & 24 & 28 & 34 & - & - & - & - \\
\hline [11] & - & 0 & 100 & - & - & - & - & 0.45 & - & - & 15.55 & 24.75 & 27.26 & - & - & - & - \\
\hline [15] & $118 \mathrm{~kg}$ & 0 & 100 & - & $841 \mathrm{~kg}$ & $522 \mathrm{~kg}$ & 321 & - & - & 19 & - & - & - & - & - & 32.5 & - \\
\hline [14] & 400 & 0 & 100 & - & - & - & 200 & 0.5 & 0.8 & - & 34.5 & - & 42 & 43 & - & - & 43 \\
\hline [15] & $118 \mathrm{~kg}$ & 3 & 97 & - & $816 \mathrm{~kg}$ & $522 \mathrm{~kg}$ & 301 & - & - & 18.5 & - & - & - & - & - & 25 & - \\
\hline [10] & 315 & 5 & 95 & 44.6 & 847.6 & 1285.5 & 132.3 & 0.42 & - & - & 23 & 27.8 & 35 & - & - & - & - \\
\hline [13] & - & 5 & 95 & - & - & - & - & - & - & - & 15.69 & 18.41 & 28.57 & - & 28.63 & - & - \\
\hline [12] & 320 & 5 & 95 & - & 806.2 & 1286.5 & 134.4 & 0.42 & - & - & 22 & 24.5 & 31 & - & - & - & - \\
\hline [15] & $118 \mathrm{~kg}$ & 6 & 94 & - & $790 \mathrm{~kg}$ & $522 \mathrm{~kg}$ & 301 & - & - & 14 & - & - & - & - & - & 19 & - \\
\hline [10] & 315 & 7.5 & 92.5 & 65.3 & 805.2 & 1285.5 & 132.3 & 0.42 & - & - & 21 & 25 & 31 & - & - & - & - \\
\hline [15] & $118 \mathrm{~kg}$ & 9 & 91 & - & $765 \mathrm{~kg}$ & $522 \mathrm{~kg}$ & 301 & - & - & 12 & - & - & - & - & - & 15.5 & - \\
\hline [13] & - & 10 & 90 & - & - & - & - & - & - & - & 23.69 & 34.87 & 38.6 & - & 38.89 & - & - \\
\hline [12] & 320 & 10 & 90 & - & 763.8 & 1286.5 & 134.4 & 0.42 & - & - & 24 & 27.5 & 35 & - & - & - & - \\
\hline [10] & 315 & 12.5 & 87.5 & 103.2 & 722.3 & 1285.5 & 132.3 & 0.42 & - & - & 18.9 & 24 & 28.25 & - & - & - & - \\
\hline [10] & 315 & 15 & 85 & 149.6 & 847.6 & 1156.86 & 132.3 & 0.42 & - & - & 22.9 & 25 & 30.25 & - & - & - & - \\
\hline [13] & - & 15 & 85 & - & - & - & - & - & - & - & 23.76 & 27.48 & 20.89 & - & 31.32 & - & - \\
\hline [12] & 320 & 15 & 85 & - & 721.3 & 1286.5 & 134.4 & 0.42 & - & - & 18 & 22 & 27.5 & - & - & - & - \\
\hline [14] & 400 & 15 & 85 & - & - & - & 200 & 0.5 & 0.7 & - & 31.5 & - & 37.5 & 39 & - & - & 40 \\
\hline [15] & $118 \mathrm{~kg}$ & 15 & 85 & - & $715 \mathrm{~kg}$ & $522 \mathrm{~kg}$ & 291 & - & - & 6.5 & - & - & - & - & - & 8.5 & - \\
\hline [11] & - & 25 & 75 & - & - & - & - & 0.5 & - & - & 12.44 & 23.852 & 26.29 & - & - & - & - \\
\hline [14] & 400 & 30 & 70 & - & - & - & 200 & 0.5 & 0.6 & - & 27.5 & - & 32 & 36 & - & - & 36.5 \\
\hline [14] & 400 & 45 & 55 & - & - & - & 200 & 0.5 & 0.55 & - & 23 & - & 24.5 & 29.5 & - & - & 29 \\
\hline [11] & - & 50 & 50 & - & - & - & 393.75 & 0.5 & - & - & 11.33 & 14.81 & 16.29 & - & - & - & - \\
\hline [14] & 400 & 60 & 40 & - & - & - & 200 & 0.5 & 0.5 & - & 18.5 & - & 20 & 25 & - & - & 26 \\
\hline [11] & - & 75 & 25 & - & - & - & 433.125 & 0.55 & - & - & 9.55 & 13.18 & 14.59 & - & - & - & - \\
\hline [11] & - & 100 & 0 & & - & - & 472.5 & 0.6 & - & - & 9.1 & 11.55 & 12.66 & - & - & - & - \\
\hline
\end{tabular}


Table 2. Tensile strength, elastic modulus, density, and workability properties of HDPE fine aggregate concrete.

\begin{tabular}{|c|c|c|c|c|c|c|c|c|c|c|c|}
\hline \multirow{3}{*}{ Reference } & \multicolumn{11}{|c|}{ Mechanical Properties } \\
\hline & \multicolumn{3}{|c|}{ Split Tensile Strength (MPa) } & \multicolumn{5}{|c|}{ Flexural Strength (MPa) } & \multirow{2}{*}{$\begin{array}{c}\text { Modulus of } \\
\text { Elasticity (GPa) }\end{array}$} & \multirow{2}{*}{$\begin{array}{l}\text { Density } \\
\left(\mathrm{Kg} / \mathrm{m}^{3}\right)\end{array}$} & \multirow{2}{*}{$\begin{array}{c}\text { Slump } \\
(\mathrm{mm})\end{array}$} \\
\hline & 7 days & 14 days & 28 days & 7 days & 14 days & 28 days & 90 days & 180 days & & & \\
\hline [10] & 2.1 & 2.72 & 3.65 & 2.92 & 3.28 & 3.88 & - & - & - & - & - \\
\hline [13] & - & - & - & - & - & - & - & - & - & - & - \\
\hline$[12]$ & 1.25 & 2.9 & 3.2 & 2.4 & 3.1 & 3.9 & - & - & - & - & - \\
\hline [11] & - & - & - & - & - & - & - & - & - & - & 90 \\
\hline$[15]$ & - & - & - & - & - & - & - & - & 27 & 2165 & - \\
\hline [14] & - & - & - & 3.75 & - & 4 & 4.15 & 4.75 & 32.5 & 2220 & - \\
\hline [15] & - & - & - & - & - & - & - & - & 20.5 & 2097 & - \\
\hline [10] & 1.28 & 2.75 & 3.33 & 2.15 & 3.1 & 3.88 & - & - & - & - & 70 \\
\hline [13] & - & - & - & - & - & - & - & - & - & - & - \\
\hline [12] & 1.25 & 2.85 & 3.45 & 2.5 & 3.8 & 4.8 & - & - & - & - & - \\
\hline [15] & - & - & - & - & - & - & - & - & 17 & 2022 & - \\
\hline [15] & - & - & - & - & - & - & - & - & 12 & 1930 & - \\
\hline [10] & 2.02 & 2.65 & 3.28 & 3.2 & 3.2 & 5.98 & - & - & - & - & 45 \\
\hline [13] & - & - & - & - & - & - & - & - & - & - & - \\
\hline [12] & 1.95 & 2.65 & 3.25 & 3.5 & 4.7 & 6.1 & - & - & - & - & - \\
\hline [10] & 1.88 & 2.38 & 2.9 & 2.28 & 2.27 & 4.82 & - & - & - & - & 40 \\
\hline [10] & 1.35 & 2.01 & 2.5 & 3.27 & 3.15 & 4.25 & - & - & - & - & 30 \\
\hline [13] & - & - & - & - & - & - & - & - & - & - & - \\
\hline [12] & 1.8 & 2.3 & 2.8 & 2.2 & 3.6 & 4.7 & - & - & - & - & - \\
\hline [14] & - & - & - & 3.25 & - & 3.3 & 3.7 & 4.4 & 24.5 & 2120 & - \\
\hline [15] & - & - & - & - & - & - & - & - & 7 & 1825 & - \\
\hline [11] & - & - & - & - & - & - & - & - & - & - & 90 \\
\hline
\end{tabular}


Table 2. Cont.

\begin{tabular}{|c|c|c|c|c|c|c|c|c|c|c|c|}
\hline \multirow{3}{*}{ Reference } & \multicolumn{11}{|c|}{ Mechanical Properties } \\
\hline & \multicolumn{3}{|c|}{ Split Tensile Strength (MPa) } & \multicolumn{5}{|c|}{ Flexural Strength (MPa) } & \multirow{2}{*}{$\begin{array}{c}\text { Modulus of } \\
\text { Elasticity (GPa) }\end{array}$} & \multirow{2}{*}{$\begin{array}{l}\text { Density } \\
\left(\mathrm{Kg} / \mathrm{m}^{3}\right)\end{array}$} & \multirow{2}{*}{$\begin{array}{l}\text { Slump } \\
(\mathrm{mm})\end{array}$} \\
\hline & 7 days & 14 days & 28 days & 7 days & 14 days & 28 days & 90 days & 180 days & & & \\
\hline [14] & - & - & - & 2.9 & - & 3.2 & 3.15 & 3.4 & 16 & 2000 & - \\
\hline$[14]$ & - & - & - & 2.5 & - & 2.5 & 3 & 3.4 & 12 & 1890 & - \\
\hline [11] & - & - & - & - & - & - & - & - & - & - & 90 \\
\hline [14] & - & - & - & 2.35 & - & 2.65 & 2.65 & 3 & 9 & 1760 & - \\
\hline [11] & - & - & - & - & - & - & - & - & - & - & 90 \\
\hline [11] & - & - & - & - & - & - & - & - & - & - & 90 \\
\hline
\end{tabular}




\subsection{Durability Characteristics of HDPE Fine Aggregate Concrete}

Water adsorption of HDPE fine aggregate concrete has increased from $5 \%$ to $10.4 \%$, when recycled HDPE content increases from $0 \%$ to $15 \%$ [15]. Similarly an increment of $5.5 \mathrm{~kg} / \mathrm{m}^{2} / \mathrm{min}$ has been observed in initial rate of adsorption (IRA) from $0.5 \mathrm{~kg} / \mathrm{m}^{2} / \mathrm{min}$ to $6.0 \mathrm{~kg} / \mathrm{m}^{2} / \mathrm{min}$, with the increase of HDPE from $0 \%$ to $15 \%$ [15]. It is observed that the chloride ion penetration is reduced and lies in the range of 2000-4000 Coulombs with the increase of HDPE content in concrete [12]. For instance, when HDPE increased from $0 \%$ to $15 \%$ in concrete, the chloride permeability has reduced from 4250 to 2700 Coulombs which is a $36.5 \%$ reduction [12].

After 28 days of curing, the Ultrasonic Pulse Velocity (UPV) test was performed on HDPE fine aggregate concrete and it is observed that the velocity has decreased from $3880 \mathrm{~m} / \mathrm{s}$ to $2720 \mathrm{~m} / \mathrm{s}$, with the increase of HDPE from $0 \%$ to $60 \%$ in $15 \%$ intervals [14]. Additionally, slight drops of $6 \mathrm{~m} / \mathrm{s}, 41 \mathrm{~m} / \mathrm{s}, 19 \mathrm{~m} / \mathrm{s}, 118 \mathrm{~m} / \mathrm{s}$ and $170 \mathrm{~m} / \mathrm{s}$ were observed in UPV at HDPE-0, HDPE-15, HDPE-30, HDPE-45 and HDPE-60, respectively, over the curing period of 28 to 90 days [14].

Thermal conductivity has dropped from $2 \mathrm{~W} / \mathrm{m} \cdot \mathrm{K}$ to $1.14 \mathrm{~W} / \mathrm{m} \cdot \mathrm{K}$ when HDPE increases from $0 \%$ to $60 \%$ at 7 days [14]. Similar readings have been observed in thermal conductivity variation for 14, 28, 90 and 365 days which are slight drops of $0.8 \mathrm{~W} / \mathrm{m} \cdot \mathrm{K}$, $0.81 \mathrm{~W} / \mathrm{m} \cdot \mathrm{K}, 0.76 \mathrm{~W} / \mathrm{m} \cdot \mathrm{K}$ and $0.69 \mathrm{~W} / \mathrm{m} \cdot \mathrm{K}$, respectively, with the increase of HDPE percentage in concrete [14]. It was also observed that thermal conductivity has dropped between 7 and 90 days, when HDPE is added from $0 \%$ to $60 \%$ in $15 \%$ intervals [14]. These reductions are recorded to be by $11 \%, 5.2 \%, 6.7 \%, 3.8 \%$ and $10.5 \%$ for HDPE- 0 , HDPE- 15 , HDPE-30, HDPE-45 and HDPE-60, respectively [14]. However, after 90 days, both standard and HDPE fine aggregate concretes have shown a stable conductivity as the decrease of thermal conductivity between 90 and 365 days are $2.8 \%, 3 \%, 0 \%, 4 \%$ and $1.9 \%$ for HDPE- 0 , HDPE-15, HDPE-30, HDPE-45 and HDPE-60 concrete, respectively [14].

\subsection{Mechanical Properties of HDPE Coarse Aggregate Concrete}

The workability (slump) of HDPE coarse aggregate concrete has reduced from $61 \mathrm{~mm}$ to $55 \mathrm{~mm}$, and to $28 \mathrm{~mm}$, when HDPE is increased from $0 \%$ to $4 \%$ in $2 \%$ intervals while keeping the water/cement (W/C) ratio at 0.55, Table 3 [16]. HDPE- 6 and HDPE-8 showed zero slump with the same $\mathrm{W} / \mathrm{C}$ ratio of 0.55 [16]. Another experiment has recorded $55 \mathrm{~mm}$ and $13 \mathrm{~mm}$ slumps at HDPE-0 and HDPE-100 concretes [17]. Both experiments have observed a reduction in the workability of the HDPE coarse aggregate concrete with the increase of HDPE. Philomina and D'Mello [18] have observed that the slump has increased from $95 \mathrm{~mm}$ to $118 \mathrm{~mm}$, an increase of $24.2 \%$, when HDPE is added from $0 \%$ to $32 \%$. Similarly, it has also observed an increment in the slump from $10 \mathrm{~mm}$ to $18 \mathrm{~mm}$ with the increase of HDPE from $0 \%$ to $30 \%$ in $10 \%$ intervals [19].

Similar to HDPE fine aggregate concrete, the compressive strength of HDPE coarse aggregate concrete decreases with the increases of HDPE percentage, Figure 4a. Lopez et al. [20] observed compressive strength reduction from 11.6 MPa to 2.3 MPa when HDPE is added from $0 \%$ to $30 \%$. Authors further noted that the variation of HDPE coarse aggregate size between $\frac{1}{2}$ " and $\frac{3}{4}$ " has not made any significant impact on the compressive strength [20]. Philomina and D'Mello [18] reported a compressive strength reduction from 42.14 MPa to $30.98 \mathrm{MPa}$ with the increase of HDPE from $0 \%$ to $32 \%$ in $8 \%$ intervals. Rahim et al. [19] have observed that the 28-days' compressive strength has dropped from 28.4 MPa to 18.24 MPa, when HDPE is added from $0 \%$ to $30 \%$ in $10 \%$ intervals, which is a drop from $28 \mathrm{MPa}$ to 15.5 MPa by Habib et al. [21], when HDPE is increased from $0 \%$ to $20 \%$ in $5 \%$ intervals and a drop of $15.9 \mathrm{MPa}$ by Kodua [16] with the increase of HDPE from $0 \%$ to $8 \%$ in $2 \%$ intervals. In another study, there is no compressive strength change noted up to $10 \%$ of HDPE incorporated in concrete, but afterwards, a little strength drop (i.e., from $26.54 \mathrm{MPa}$ to $22.45 \mathrm{MPa}$ ) was observed when HDPE is added from $10 \%$ to $30 \%$ [22]. Similarly, the compressive strength has decreased from $34 \mathrm{MPa}$ to $28.5 \mathrm{MPa}$ with the increase of HDPE from $0 \%$ to $10 \%$, an increment of $5.5 \mathrm{MPa}$ during $10 \%$ to $15 \%$ increase and again, a drop of $5.5 \mathrm{MPa}$, 
when HDPE is increased from $15 \%$ to $20 \%$ [12]. It is identified that optimum 28-days compressive strength of $34 \mathrm{MPa}$ is achieved at HDPE-15 [12]. However, Lopez et al. [20] suggest that optimum 28-days' compressive strength is obtained at HDPE-10.

The splitting tensile strength also shows a decreasing trend with the increment of HDPE content, Figure $4 \mathrm{~b}[12,18,21]$. A tensile strength reduction of $1.4 \mathrm{MPa}$ (is observed at 28 days with the increase of HDPE from $0 \%$ to $20 \%$ [21]. There is no tensile strength change recorded until HDPE is added up to $8 \%$, but $0.8 \mathrm{MPa}$ strength reduction was noted when HDPE increased to 32\% [18]. Shanmugapriya and Santhi [12] noted the contradicted behavior illustrating a significant splitting tensile strength reduction of $23.4 \%$ when incorporated with 10\% HDPE in concrete. However, tensile strength gain (26.5\%) was observed with the increase of HDPE content from $10 \%$ to $15 \%$ and, again, a drop of $16.1 \%$ when HDPE increased from $15 \%$ to $20 \%$ [12]. It is identified that HDPE- 15 achieves the optimum 28-days' splitting tensile strength.
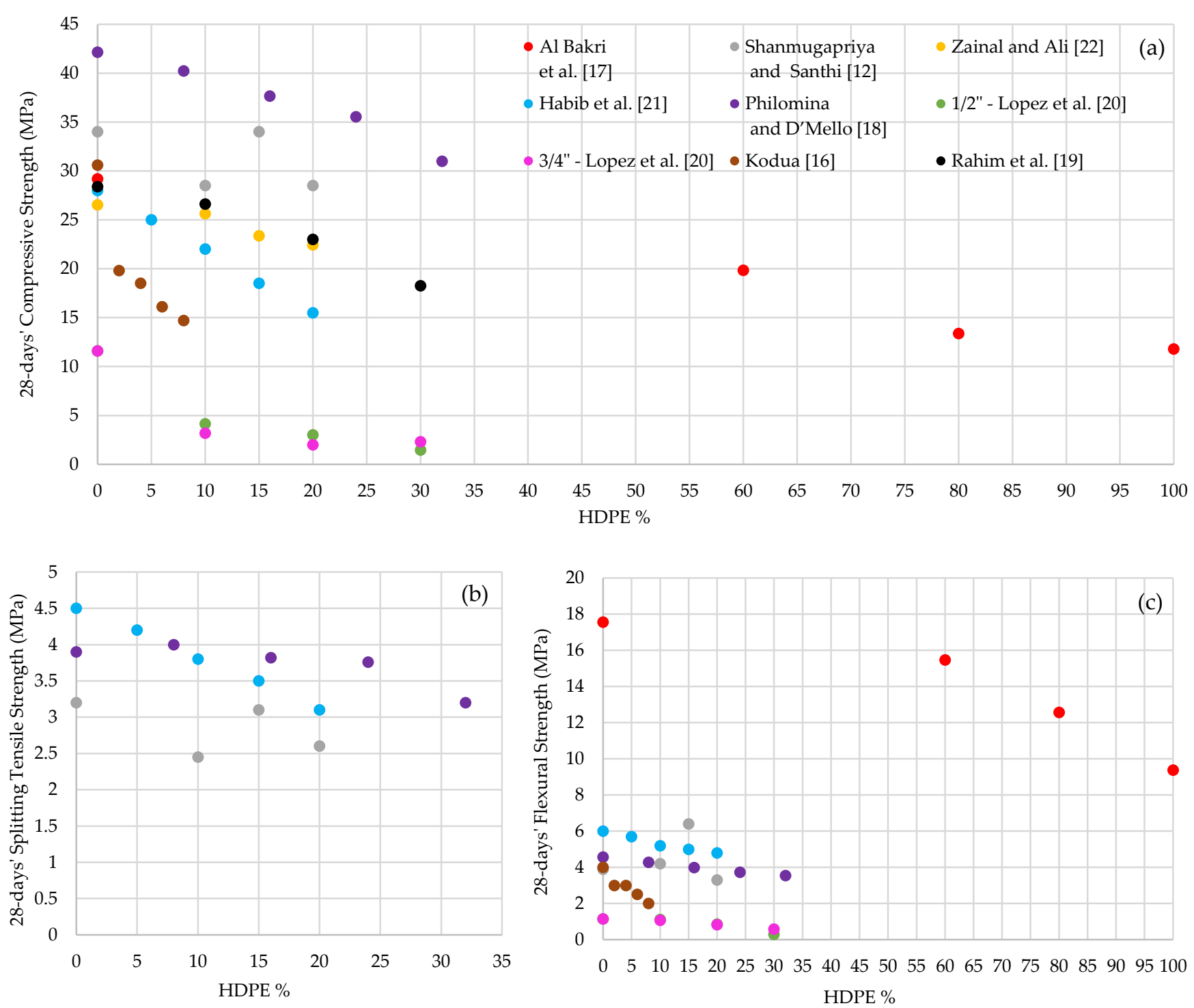

Figure 4. 28-days' (a) Compressive strength; (b) Splitting tensile strength and (c) Flexural strength variations of HDPE coarse aggregate concrete. 
Table 3. Mechanical properties of HDPE coarse aggregate concrete.

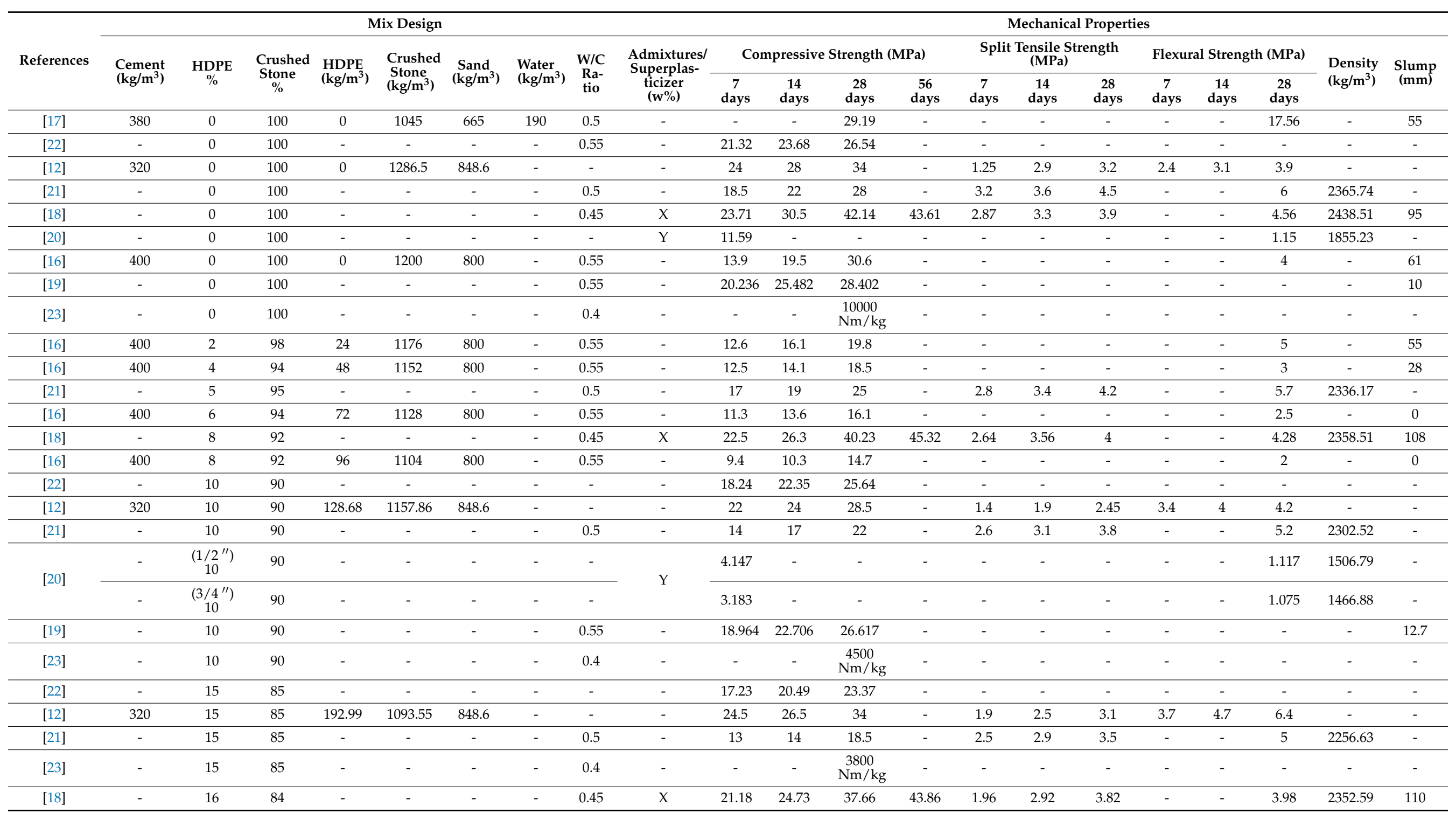


Table 3. Cont.

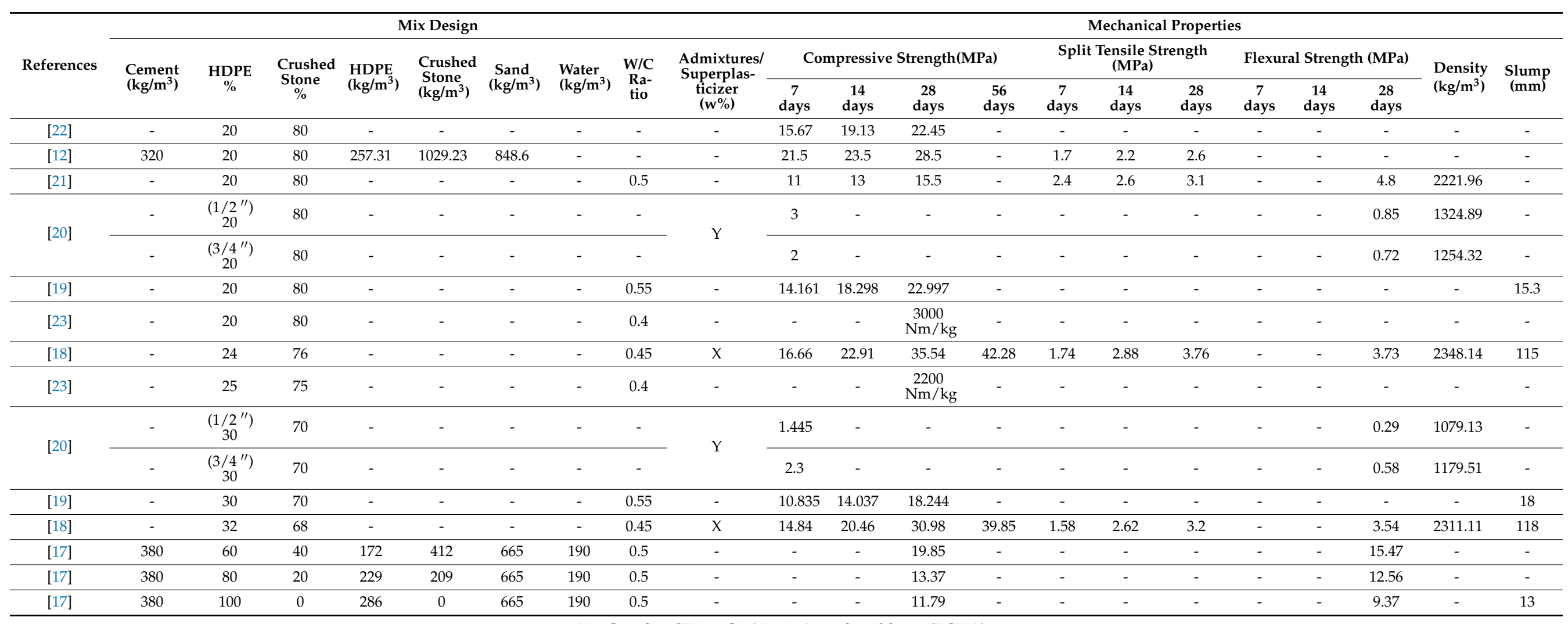

$\mathrm{X}=$ Conplast $\mathrm{SP} 430 \mathrm{G} 8 ; \mathrm{Y}=15 \%$ acrylic additive (PCHA). 
Flexural strength or bending strength reduces with the increase of HDPE when incorporated as coarse aggregate in concrete Figure 4c. Bakri et al. [17] noted that the flexural strength decreased from 17.56 MPa to 15.47 MPa with the increase of HDPE content up to $60 \%$. The flexural strength has dropped by 6.1 MPa when the HDPE is added from $60 \%$ to $100 \%$ [17]. It has also been observed that the 28-days' flexural strength of HDPE coarse aggregate concrete is dropped by $1.9 \mathrm{MPa}$ (from $6 \mathrm{MPa}$ to $4.1 \mathrm{MPa}$ ) when HDPE increases from $0 \%$ to $20 \%$ in $5 \%$ intervals [21]. A 2 MPa flexural strength drop is observed with the increase of HDPE from $0 \%$ to $8 \%$ [16,18,20]. Shanmugapriya and Santhi [12] observed the opposite trend as a $2.5 \mathrm{MPa}$ flexural strength gain obtained at 28 days for HDPE-15 concrete. The same experiment has achieved the optimum 28-days' flexural strength of $6.4 \mathrm{MPa}$ at HDPE-15, followed by a drop of 3.1 MPa, when HDPE is increased by another $5 \%$ [12]. It is noted that the optimum 28-days' flexural strength is attained in different HDPE percentages: for instance, 6.4 MPa at HDPE-15 (Shanmugapriya and Santhi) [12], 4.28 MPa at HDPE-8 (Philomina and D'Mello) [18] and 1.075 MPa at HDPE-10 (Lopez et al.) [20].

The density of HDPE coarse aggregate concrete is decreased with the increase of HDPE content, Table $3[18,20,21]$. It is observed that there was a $5.2 \%$ reduction in density with the increase of HDPE from $0 \%$ to $32 \%$ and a $6.1 \%$ reduction during $0 \%$ to $20 \%$ of HDPE addition [12,21]. The density of $\frac{1}{2}^{\prime \prime}$ HDPE coarse aggregate concrete matrix has reduced by $776.1 \mathrm{~kg} / \mathrm{m}^{3}$ and by $675.72 \mathrm{~kg} / \mathrm{m}^{3}$ in $\frac{3}{4}{ }^{\prime \prime}$ HDPE coarse aggregate concrete matrix only with the increase of HDPE from $0 \%$ to $30 \%$ [20]. This reveals that a greater density drop could be achieved when the aggregate size is reduced from $\frac{3}{4}$ " to $\frac{1}{2}^{\prime \prime}$ regardless of the HDPE inclusion percentage. Another notable observation is that the rate of reduction of dry density was $0.2 \%$ per volume percent of waste polymer added in HDPE coarse aggregate concrete [23].

\subsection{Durability Characteristics of HDPE Coarse Aggregate Concrete}

Porosity and permeability of HDPE coarse aggregate concrete have increased with the increase of HDPE content [20]. The HDPE-0 standard concrete displayed a porosity of 22.67 and increased it up to 36.21 when HDPE was added to 30\% [20]. The typical value of permeability of a pervious concrete ranges from 0.135 to $1.219 \mathrm{~cm} / \mathrm{s}$ and all the HDPE coarse aggregate concretes display a higher permeability than the range specified [20]. Permeability of $\frac{1}{2}^{\prime \prime} \mathrm{HDPE}$ coarse aggregate concrete has increased by $5.28 \mathrm{~cm} / \mathrm{s}$, when the HDPE increases from $0 \%$ to $30 \%$ in $10 \%$ intervals [20]. Similarly, the permeability was increased by $4.03 \mathrm{~cm} / \mathrm{s}$, when $\frac{3}{4} /$ HDPE coarse aggregates are increased in the same range [20]. It can be noted that the permeability of HDPE coarse aggregate concrete of this research study has exceeded the industry standards and varies between 0.135467 to $1.2192 \mathrm{~cm} / \mathrm{s}$ [20]. Moreover, the porosity of HDPE coarse aggregate concrete has increased by $65 \%$ and $59.7 \%$, with the increase of HDPE from $0 \%$ to $30 \%$ for $\frac{1}{2}{ }^{\prime \prime}$ and $\frac{3}{4}$ ' aggregate sizes, respectively. An extensive study carried out on sorptivity of HDPE coarse aggregate concrete results in a drop of $45.4 \%$ in sorptivity with the increase of HDPE from $0 \%$ to $32 \%$ [18].

Water absorption rate of HDPE coarse aggregate concrete is increased by $34.7 \%$, when the HDPE increase from $0 \%$ to $20 \%$ [22]. In another experiment, a similar gain, $35.5 \%$ in water absorption was observed with the increase of HDPE content to 8\% [16]. However, Philomina and D'Mello [18] have observed a 6.13\% drop (from 4.4\% to $4.13 \%$ ) in water absorption rate of HDPE coarse aggregate concrete when HDPE is added from $0 \%$ to $32 \%[18]$.

At direct UPV test, the pulse velocity of HDPE coarse aggregate concrete has increased from $4200 \mathrm{~m} / \mathrm{s}$ to $4650 \mathrm{~m} / \mathrm{s}$, when HDPE is added from $0 \%$ to $16 \%$ [18]. After reaching the maximum velocity, $4650 \mathrm{~m} / \mathrm{s}$ at HDPE-16, a drop of $560 \mathrm{~m} / \mathrm{s}$ was recorded with the increase of HDPE from $16 \%$ to $32 \%$ [18]. The same experiment has performed an indirect UPV test for HDPE coarse aggregate concrete. Initially, the velocity is increased by $560 \mathrm{~m} / \mathrm{s}$, when HDPE increases from $0 \%$ to $8 \%$ [18]. Then, an $830 \mathrm{~m} / \mathrm{s}$ velocity drop during $8 \%$ to 
$16 \%$ HDPE addition is observed, followed by a $1030 \mathrm{~m} / \mathrm{s}$ velocity gain with the increase of HDPE from $16 \%$ to $24 \%$ and, finally, a drop of $1860 \mathrm{~m} / \mathrm{s}$, when HDPE is added from $24 \%$ to $32 \%$ [18]. The same study has carried out the rebound hammer test and have obtained rebound values at 56-days' compressive strength [18]. The 56-day rebound values have increased from 40 to 42 when HDPE is added from $0 \%$ to $8 \%$ and then have dropped from 42 to 36 with the increase of HDPE from $8 \%$ to $32 \%$ [18]. Compressive strength obtained through rebound hammer test as well as through a destructive test show similar increments by $2.1 \mathrm{MPa}$ and $1.71 \mathrm{MPa}$ when HDPE increases from $0 \%$ to $8 \%$ and drops by $6.32 \mathrm{MPa}$ and $5.47 \mathrm{MPa}$ when HDPE is added from $8 \%$ to $32 \%$, respectively [18].

When considering the sulphate attack test, the compressive strength of HDPE coarse aggregate concrete (with the increase of HDPE from $0 \%$ to $32 \%$ ) is increased when immersed with Na2SO4 apart from the standard concrete matrix (HDPE-0) [18]. Compressive strength is observed to be dropped by $1.48 \mathrm{MPa}$ in the standard concrete matrix (HDPE-0) after immersion in Na2SO4 [18]. Compressive strength is increased by $0.33 \mathrm{MPa}, 0.51 \mathrm{MPa}$, $0.58 \mathrm{MPa}$ and 1.63 MPa at HDPE-8, HDPE-16, HDPE-24 and HDPE-32 concretes, respectively [18]. This has further displayed a $6.25 \%$ of weight loss due to a sulphate attack test in HDPE coarse aggregate concrete with the increase of HDPE from $0 \%$ to $32 \%$ [18].

An acid attack test was carried out through a comparison of compressive strength values obtained after immersing HDPE coarse aggregate concrete mixes in both water and hydrochloric $(\mathrm{HCl})$ acid after curing for 28 days [18]. When the HDPE is increased from $0 \%$ to $32 \%$ in $8 \%$ intervals, the compressive strength has reduced by $12.21 \mathrm{MPa}$ and $12.45 \mathrm{MPa}$ after immersion in $\mathrm{HCl}$ acid and water, respectively. When comparing the compressive strength drop of each HDPE coarse aggregate concrete matrix: HDPE-0, HDPE-8, HDPE-16, HDPE-24 and HDPE-32 due to immersion in $\mathrm{HCl}$ acid is recorded to be $2.7 \%, 5.0 \%, 4.1 \%, 3.31 \%$ and $2.97 \%$, respectively [18]. The least compressive strength drop was recorded in HDPE-0 concrete matrix and, however, it can be observed that the compressive strength drop has reduced significantly with an increase of HDPE. The same experiment has observed an increase of $54.5 \%$ in weight loss percentage, with the increase of HDPE from $0 \%$ to $32 \%$ [18]. According to Kodua [16], when concrete mixes are immersed in nitric (HNO3) acid solution, compressive strength of HDPE coarse aggregate concrete is decreased by $53.9 \%$ with the increase of HDPE from $0 \%$ to $8 \%$. An increase in weight loss of $34.1 \%$ was also observed, after immersing in HNO3, when HDPE is increased from $0 \%$ to $8 \%$ [16]. Therefore, the effects imposed due to acids on HDPE coarse aggregate concrete are very minimal and can withstand the chemical reactions within the concrete [18].

\section{Use of HDPE as a Fiber Reinforcement in Concrete}

\subsection{Mechanical Properties of HDPE Fiber Reinforced Concrete}

Table 4 illustrates that the workability (slump) of HDPE fiber reinforced concrete was reduced by $73.8 \%$ when adding $1.25 \%$ of HDPE fibers having a diameter of $0.25 \mathrm{~mm}$ and a length of $23 \mathrm{~mm}$ while maintaining the same w/c ratio of 0.62 [24,25]. Pešić et al. [24] reveal that varying the fiber diameter from $0.25 \mathrm{~mm}$ to $0.4 \mathrm{~mm}$ and length from $23 \mathrm{~mm}$ to $30 \mathrm{~mm}$, has reduced the slump by $3 \mathrm{~mm}$ at HDPE- 0.4 and by $4 \mathrm{~mm}$ at HDPE- 0.75 and HDPE-1.25. It also suggests that increasing the water content used in HDPE concrete matrix and adding water-reducing agents can prevent segregation of plastic fibers in the reinforced concrete mixes [26]. As a result, Dehydol LS-12 (LS-12) nonionic surfactant is used to increase the wettability of plastic materials [26]. With the addition of the Dehydol LS-12, it was observed that the slump values are decreased from $130 \mathrm{~mm}$ to $20 \mathrm{~mm}$ when $\mathrm{w} / \mathrm{c}$ ratio is increased from 0.5 to 0.6 and the HDPE fiber are increased from $0 \%$ to $30 \%$ [26]. 
Table 4. Mechanical properties of HDPE fiber reinforced concrete.

\begin{tabular}{|c|c|c|c|c|c|c|c|c|c|c|c|c|c|c|c|c|c|c|c|c|}
\hline \multirow{3}{*}{ Reference } & \multicolumn{9}{|c|}{ Mix Design } & \multicolumn{11}{|c|}{ Mechanical Properties } \\
\hline & \multirow{2}{*}{$\begin{array}{l}\text { Cement } \\
\left(\mathrm{kg} / \mathrm{m}^{3}\right)\end{array}$} & \multicolumn{3}{|c|}{ HDPE } & \multirow{2}{*}{$\begin{array}{l}\mathrm{HDPE} \\
\left(\mathbf{k g} / \mathrm{m}^{3}\right)\end{array}$} & \multirow{2}{*}{$\begin{array}{c}\text { Crushed } \\
\text { Stone } \\
\left(\mathrm{kg} / \mathrm{m}^{3}\right)\end{array}$} & \multirow{2}{*}{$\underset{\left(\mathrm{kg} / \mathrm{m}^{3}\right)}{\text { Sand }}$} & \multirow{2}{*}{$\begin{array}{c}\text { Water } \\
\text { Content } \\
\left(\mathrm{kg} / \mathrm{m}^{3}\right)\end{array}$} & \multirow{2}{*}{$\begin{array}{l}\text { W/C } \\
\text { Ratio }\end{array}$} & \multicolumn{3}{|c|}{$\begin{array}{l}\text { Compressive } \\
\text { Strength (MPa) }\end{array}$} & \multicolumn{3}{|c|}{$\begin{array}{c}\text { Split Tensile Strength } \\
\text { (MPa) }\end{array}$} & \multicolumn{2}{|c|}{$\begin{array}{c}\text { Flexural Strength } \\
(\mathrm{MPa})\end{array}$} & \multirow{2}{*}{$\begin{array}{l}\text { Modulus of } \\
\text { Elasticity } \\
\text { (GPa) }\end{array}$} & \multirow{2}{*}{$\begin{array}{c}\text { Bulk } \\
\text { Density } \\
\left(\mathrm{kg} / \mathrm{m}^{3}\right)\end{array}$} & \multirow{2}{*}{$\begin{array}{l}\text { Slump } \\
(\mathrm{mm})\end{array}$} \\
\hline & & $\begin{array}{c}\mathrm{L} \\
(\mathrm{mm})\end{array}$ & $\underset{(\mathrm{mm})}{\mathrm{d}}$ & $\%$ & & & & & & 7 days & $\begin{array}{c}28 \\
\text { days }\end{array}$ & $\begin{array}{c}90 \\
\text { days }\end{array}$ & 7 days & $\begin{array}{c}28 \\
\text { days }\end{array}$ & $\begin{array}{c}90 \\
\text { days }\end{array}$ & 7 days & 28 days & & & \\
\hline [24] & 380 & - & - & 0 & 0 & 860 & 780 & 235 & 0.62 & - & 33.2 & 38.1 & - & 2.79 & 3.32 & - & - & 24.2 & - & 65 \\
\hline [25] & - & - & - & 0 & 0 & - & - & - & - & - & 33.2 & 38.1 & - & 2.79 & 3.32 & - & - & 24.2 & - & 65 \\
\hline [27] & - & - & - & 0 & 0 & - & - & - & 0.42 & 25 & 37 & - & 3 & 3.75 & - & 1.7 & 3.4 & - & - & - \\
\hline [26] & $33 \mathrm{~kg}$ & - & - & 0 & 0 & - & $66 \mathrm{~kg}$ & $16.5 \mathrm{~kg}$ & 0.5 & - & 26 & - & - & 3 & - & - & - & - & 1950 & 130 \\
\hline [24] & 380 & 30 & 0.4 & 0.4 & - & 860 & 780 & 235 & 0.62 & - & 31 & 37.2 & - & 3.03 & 3.4 & - & - & 24.2 & - & 33 \\
\hline [25] & - & 23 & 0.25 & 0.4 & - & - & - & - & - & - & 34.3 & 40.1 & - & 3.08 & 3.47 & - & - & 24.5 & - & 36 \\
\hline [27] & - & - & - & 0.5 & - & - & - & - & - & 29 & 37 & - & 2.9 & 3.8 & - & 1.75 & 3.45 & - & - & - \\
\hline [24] & 380 & 23 & 0.25 & 0.75 & - & 860 & 780 & 235 & 0.62 & - & 31.1 & 38.4 & - & 2.95 & 3.49 & - & - & 24.9 & - & 22 \\
\hline [24] & 380 & 30 & 0.4 & 0.75 & - & 860 & 780 & 235 & 0.62 & - & 31 & 37.7 & - & 2.93 & 3.47 & - & - & 25.9 & - & 18 \\
\hline [25] & - & 23 & 0.25 & 0.75 & - & - & - & - & - & - & 31.1 & 38.4 & - & 2.95 & 3.49 & - & - & 24.9 & - & 22 \\
\hline [27] & - & - & - & 1 & - & - & - & - & - & 29.5 & 37.5 & - & 3.2 & 3.85 & - & 1.9 & 3.45 & - & - & - \\
\hline [24] & 380 & 23 & 0.25 & 1.25 & - & 860 & 780 & 235 & 0.62 & - & 32.3 & 37.7 & - & 2.96 & 3.43 & - & - & 25.2 & - & 17 \\
\hline [25] & - & 23 & 0.25 & 1.25 & - & - & - & - & - & - & 32.3 & 37.7 & - & 2.96 & 3.43 & - & - & 25.2 & - & 17 \\
\hline [27] & - & - & - & 1.5 & - & - & - & - & - & 30 & 38 & - & 3.3 & 3.9 & - & 2 & 3.6 & - & - & - \\
\hline [27] & - & - & - & 2 & - & - & - & - & - & 30.5 & 38.5 & - & 3.4 & 4.1 & - & 2.1 & 3.65 & - & - & - \\
\hline [27] & - & - & - & 2.5 & - & - & - & - & - & 31 & 39 & - & 2.4 & 4.25 & - & 2.1 & 3.8 & - & - & - \\
\hline [27] & - & - & - & 3 & - & - & - & - & - & 32 & 39 & - & 3.6 & 4.3 & - & 2.2 & 4.9 & - & - & - \\
\hline [27] & - & - & - & 3.5 & - & - & - & - & - & 33 & 40 & - & 3.7 & 4.4 & - & 2.25 & 4.2 & - & - & - \\
\hline [27] & - & - & - & 4 & - & - & - & - & - & 30.5 & 38.5 & - & 3.6 & 4.2 & - & 2.2 & 4 & - & - & - \\
\hline [27] & - & - & - & 4.5 & - & - & - & - & - & 30 & 37.5 & - & 3.55 & 4.1 & - & 2.1 & 3.9 & - & - & - \\
\hline [27] & - & - & - & 5 & - & - & - & - & - & 29.5 & 36.5 & - & 3.5 & 3.9 & - & 2.05 & 3.8 & - & - & - \\
\hline [26] & $30.12 \mathrm{~kg}$ & - & - & 5 & 0.14 & - & $60.24 \mathrm{~kg}$ & 15.06 & 0.5 & - & 16.5 & - & - & 1.8 & - & - & - & - & - & - \\
\hline [27] & - & - & - & 5.5 & - & - & & - & - & 29 & 36 & - & 3.4 & 3.8 & - & 2 & 3.7 & - & - & - \\
\hline [27] & - & - & - & 6 & - & - & & - & - & 27.5 & 34.5 & - & 3.3 & 3.7 & - & 1.9 & 3.6 & - & - & - \\
\hline [26] & $30.12 \mathrm{~kg}$ & - & - & 10 & 0.28 & - & $60.24 \mathrm{~kg}$ & $15.05 \mathrm{~kg}$ & 0.5 & - & 12 & - & - & 1.9 & - & - & - & - & 1750 & 60 \\
\hline [26] & $30.12 \mathrm{~kg}$ & - & - & 15 & 0.42 & - & $60.24 \mathrm{~kg}$ & $16.57 \mathrm{~kg}$ & 0.55 & - & 9 & - & - & 1.3 & - & - & - & - & - & - \\
\hline [26] & $30.12 \mathrm{~kg}$ & - & - & 20 & 0.56 & - & $60.24 \mathrm{~kg}$ & $18.07 \mathrm{~kg}$ & 0.6 & - & 5.5 & - & - & 0.7 & - & & & - & 1800 & 48 \\
\hline [26] & $30.12 \mathrm{~kg}$ & - & - & 30 & 0.84 & - & $60.24 \mathrm{~kg}$ & $18.07 \mathrm{~kg}$ & 0.6 & - & - & - & - & - & - & & & - & 1677 & 20 \\
\hline
\end{tabular}


As illustrated in Figure 5a, the compressive strength has decreased by $8.13 \%$ when HDPE fibers with a diameter of $0.4 \mathrm{~mm}$ are added from $0 \%$ to $1.25 \%$ [24]. Moreover, when the HDPE fiber diameter is $0.25 \mathrm{~mm}$, the compressive strength has increased by $3.3 \%$ with the increase of HDPE fibers from $0 \%$ to $0.4 \%$ and, again, dropped by $5.8 \%$ when fibers are added from $0.4 \%$ to $1.25 \%$ [24,25]. Malagavelli and Patura [27] showed that the optimum compressive strength of $40 \mathrm{MPa}$ was achieved by HDPE-3.5 concrete when the fiber content is varied between $0 \%$ and $6 \%$. When the fibers are added by $5 \%$ intervals from $0 \%$ to $20 \%$, the compressive strength has significantly dropped from $26 \mathrm{MPa}$ to $20 \mathrm{MPa}$ [26]. However, it has been identified that the large volume fraction of HDPE fibers often lowers the compressive strength of concrete [26]. Poonyakan et al. [26] have suggested that all concrete used for precast wall panels (non-structural load carrying) must have a minimum compressive strength of $16 \mathrm{MPa}$ which can be fulfilled by adding HDPE fibers up to 5\% [26].
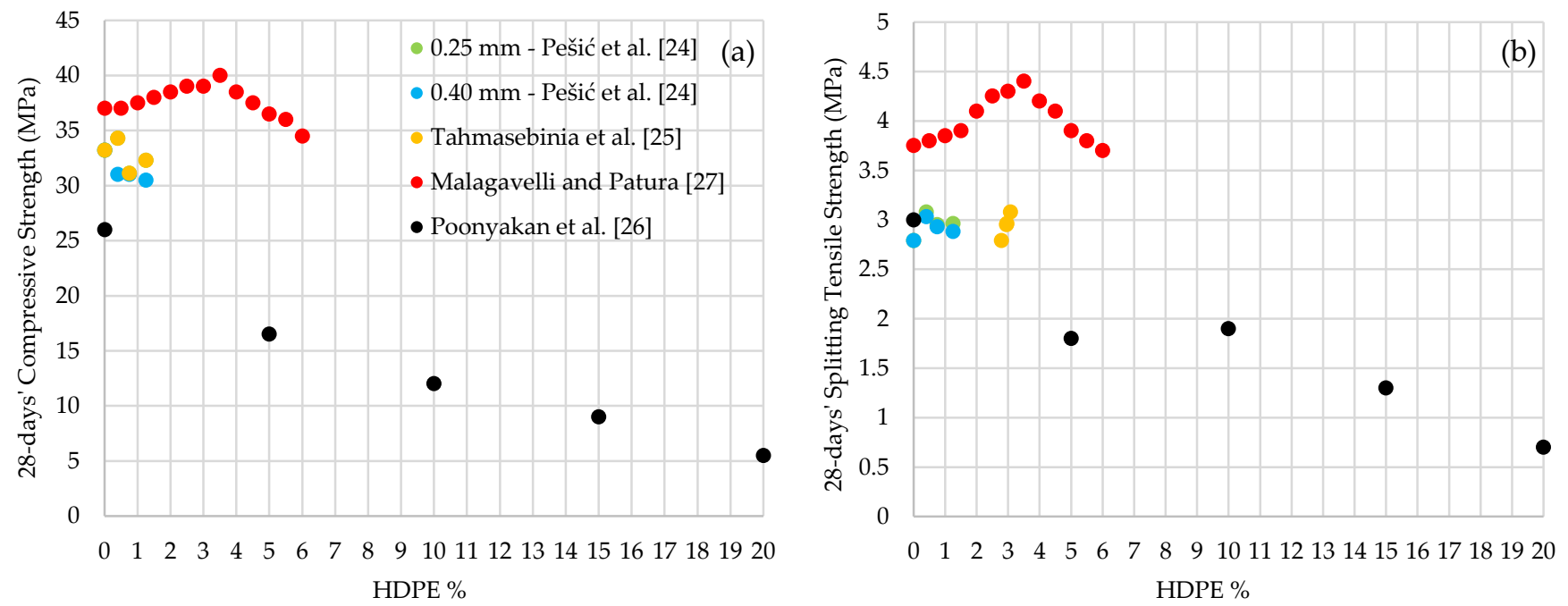

Figure 5. 28-days' (a) Compressive strength and (b) Split tensile strength variations of HDPE fiber reinforced concrete.

The 28-days' splitting tensile strength of HDPE fiber reinforced concrete has increased by $10.4 \%$, when fibers with $0.25 \mathrm{~mm}$ diameter are added from $0 \%$ to $0.4 \%$ and again a $3.9 \%$ drop is observed, when fibers are added from $0.4 \%$ to $1.25 \%$, Figure $5 b$ [24,25]. Similarly, the splitting tensile strength has increased from $2.79 \mathrm{MPa}$ to $3.03 \mathrm{MPa}$, when fibers with $0.40 \mathrm{~mm}$ diameter are added from $0 \%$ to $0.4 \%$, and a drop of $0.15 \mathrm{MPa}$ is observed, when HDPE fibers are added from $0.4 \%$ to $1.25 \%$ [24]. Similar to compressive strength observations, Malagavelli and Patura [27] have observed the optimum splitting tensile strength of 4.4 MPa at HDPE-3.5, when the fiber content varied between $0 \%$ and $6 \%$. In another experiment, the splitting tensile strength has dropped by $40 \%$ with the increase of HDPE from $0 \%$ to $5 \%$, followed by a slight gain of 5.6\% at HDPE- 10 and then, again, tensile strength has dropped by $63.2 \%$, when HDPE fibers are added from $10 \%$ to $20 \%$ [26]. On the other hand, the 28-days' flexural strength of HDPE fiber reinforced concrete is always greater than the standard concrete (HDPE-0) regardless of the HDPE fiber percentage being added, Table 4 [27]. It is observed that, the flexural strength has increased from 3.4 MPa to an optimum of 4.9 MPa when the HDPE fibers are added from $0 \%$ to $3 \%$ in $0.5 \%$ intervals and then the flexural strength has dropped by $1.3 \mathrm{MPa}$ when the HDPE fibers are added from $3 \%$ to $6 \%$ in $0.5 \%$ intervals [27].

A slight increase (1.0 GPa) is observed in the elastic modulus of HDPE fiber reinforced concrete with the increase of $0.25 \mathrm{~mm}$ diameter HDPE fibers from $0 \%$ to $1.25 \%$, Table 4 [24]. The same experiment shows that the elastic modulus has increased by $1.3 \mathrm{GPa}$, when the $0.4 \mathrm{~mm}$ diameter HDPE fibers are added from $0 \%$ to $1.25 \%$ [24]. 


\subsection{Durability Characteristics of HDPE Fiber Reinforced Concrete}

When considering the water permeability after 45 days, it has been identified that, the height of water penetration in HDPE fiber reinforced concrete has reduced from $43 \mathrm{~mm}$ to $26 \mathrm{~mm}$, when HDPE fibers with $0.4 \mathrm{~mm}$ diameter are added from $0 \%$ to $1.25 \%$ [24]. Similarly, HDPE fibers with $0.25 \mathrm{~mm}$ diameter have reduced the height of water penetration from $43 \mathrm{~mm}$ to $28 \mathrm{~mm}$ in similar HDPE percentages [24]. HDPE fiber reinforced concrete has contributed in reducing the water intake from $35 \%$ to $80 \%$ with the increase of HDPE fibers from $0.40 \%$ to $1.25 \%$ compared to HDPE-0 standard concrete [24]. Poonyakan et al. [26] have observed that the porosity of the HDPE fiber reinforced concrete has increased by $45 \%$ when HDPE is added from $0 \%$ to $30 \%$. Hence, it has been identified that the recycled HDPE fibers greatly improve the durability of concrete.

It has been observed that the overall number of cracks and the widths of cracks were reduced in HDPE fiber reinforced concrete when compared with the standard concrete [24]. Average crack width and the maximum crack width of $0.25 \mathrm{~mm}$ HDPE fiber reinforced concrete have been reduced by $83.63 \%$ and $81.8 \%$, respectively when HDPE fibers are added from $0 \%$ to $1.25 \%$ [24]. Similarly, average crack width and the maximum crack width of $0.4 \mathrm{~mm}$ HDPE fiber reinforced concrete have been reduced by $76.4 \%$ and $77.3 \%$ when HDPE fibers are added from $0 \%$ to $1.25 \%$ [24]. Crack reduction ratio of $0.25 \mathrm{~mm}$ and $0.4 \mathrm{~mm}$ HDPE fiber reinforced concrete increased from $34.5 \%$ to $83.6 \%$, and from $54.5 \%$ to $76.4 \%$ when HDPE fibers are increased from $0.4 \%$ to $1.25 \%$, compared with the standard concrete matrix (HDPE-0) [24].

\section{Use of HDPE as a Cement Binder}

Aattache et al. [28] investigated the cement replacement using HDPE up to $6 \%$. It is observed that the 28-days' compressive strength has decreased from $37 \mathrm{MPa}$ to $22 \mathrm{MPa}$, which is a $40.5 \%$ drop, when HDPE is added from $0 \%$ to $6 \%$ [28]. Similarly, the 7-day and 90-day compressive strength variations display decreasing trends with a strength drop of $46.7 \%$ and $28.6 \%$, respectively, with the increase of similar HDPE percentages [28]. Similar to compressive strength, the splitting tensile strength also decreases with the increase of HDPE from $0 \%$ to $6 \%$ in $2 \%$ intervals over 7,28 and 90 days [28]. They have observed tensile strength decrease of $1.7 \mathrm{MPa}, 3.9 \mathrm{MPa}$ and $3.2 \mathrm{MPa}$ at 7, 28 and 90 days, respectively, with the use of HDPE in 6\% [28].

HDPE has a comparatively low thermal conductivity of $0.33 \mathrm{~W} / \mathrm{m} \cdot \mathrm{K}$ compared with the concrete [28]. It was observed that the thermal conductivity of cement replaced HDPE concrete is decreased with the increase of HDPE [28]. At $20{ }^{\circ} \mathrm{C}$, the 28-days' thermal conductivity of cement replaced HDPE concrete is decreased by $15.6 \%$, when HDPE is increased from $0 \%$ to $6 \%$ in $2 \%$ intervals [28]. Similar observations are recorded for 28 -days thermal conductivity for $140{ }^{\circ} \mathrm{C}, 250{ }^{\circ} \mathrm{C}$ and $350{ }^{\circ} \mathrm{C}$ which reduce by $15.8 \%, 22.2 \%$ and $12 \%$, respectively. Thermal conductivity of cement replaced HDPE concrete is decreased with an increase of temperature from $20^{\circ} \mathrm{C}$ to $350{ }^{\circ} \mathrm{C}$, when HDPE is added up to $6 \%$ [28]. It was also observed that concrete mixes with a superplasticizer have a higher thermal conductivity in comparison with the standard concrete matrix (HDPE-0) since the 28th day [28].

On the other hand, Naik et al. [29] investigated the use of HDPE as a filler material in concrete, where HDPE is added up to $2 \%$ in $0.5 \%$ intervals. It was observed that the 28-days' compressive strength of HDPE filler concrete was increased by $2.5 \%$, when HDPE is added from $0 \%$ to $0.5 \%$ [29]. Then, a drop of $46.3 \%$ has been observed in compressive strength with the increase of HDPE from $0.5 \%$ to $2 \%$ in $0.5 \%$ intervals [29]. Similar gains of $3.2 \%$ and $13 \%$ were observed for 3-day and 7-day compressive strengths, respectively, when HDPE is increased from $0 \%$ to $0.5 \%$ [29]. Additionally, $25 \%$ and $42.3 \%$ drops in 3 -day and 7-day compressive strength were observed when HDPE increased from $0.5 \%$ to $2 \%$ [29]. 


\section{Discussion}

The aggregate shape, size, and surface texture influence the concrete workability and the bond between aggregates and cement/binder matrix, which in turn impact the mechanical performance in concrete [17]. Slump of HDPE coarse aggregate concrete is varied between $0 \mathrm{~mm}$ and $25 \mathrm{~mm}$ with the increase of HDPE percentage. This is due to the fact that the low workability in the concrete matrix is a result of some HDPE particles being angular and the rest having non-uniform shapes [19]. These different and non-uniform shaped HDPE particles considerably fail in filling the voids with HDPE fine and coarse aggregates and obstruct the flow of the concrete mix, with the increase of HDPE fine and coarse aggregates $[16,19]$. The reason for the reduction of density in HDPE aggregate concrete with the increase of HDPE is mainly due to the difference in the densities of HDPE and sand and the lower unit weight of HDPE $[14,23]$ The density of sand and HDPE is $1600 \mathrm{~kg} / \mathrm{m} 3$ and $950 \mathrm{~kg} / \mathrm{m} 3$, respectively, which is HDPE being about $40 \%$ lighter than the sand [14]. Therefore, the overall density of the HDPE fine aggregate concrete is decreased with the increase of HDPE content in concrete [15].

There are various techniques used to evaluate the performance of concrete. Scanning Electron Microscopy (SEM) images are used to examine the microstructure development of the HDPE incorporated concrete. Similarly, nanoindentation is used to observe the interfacial transition zone (ITZ) of the concrete matrix and Computed Tomography (CT) to identify the pore-structure of the concrete. Poor bond capacity and the availability of higher air content in the concrete matrix with the inclusion of HDPE aggregates is due to the non-reactive (chemically inert) behavior that leads to reduced mechanical and durability performance of HDPE aggregate concrete [30]. Weaker bonds and lower adhesion strength between cement paste and the HDPE aggregates have occurred mainly due to the hydrophobic nature and the smooth and glossy surface texture of the HDPE particles in rounded shape than a crushed aggregate $[14,15,17]$. Hydrophobic nature of HDPE results in weaker bonds with lesser strength between cement/binder matrix and HDPE aggregates at the interfacial transition zone (ITZ) when compared with the ITZ formed between natural fine aggregates (sand) and cement paste, Figures 6 and 7 [14]. These weaker bonds have resulted in reducing the compressive and tensile strengths and the modulus of elasticity of both HDPE fine and coarse aggregate concretes with the increase of recycled HDPE percentage $[12,14,19,22,23]$. Apart from the weaker bonds between cement paste and HDPE particles, hydrophobic effect further limits the inhibition of the cement hydration by restricting the movement of water, and may lead to reduce both durability and mechanical performances of HDPE fine and coarse aggregate concrete with the increase of HDPE [30]. Additionally, higher porosity and large air bubbles entrapped in the HDPE fine and coarse aggregate concrete can result in reducing the compressive strength with the increase of HDPE $[10,12,14,15]$. This ductile behavior in HDPE can significantly reduce crack formation and propagation in concrete as the cracks are being trapped by the HDPE particles [12]. HDPE aggregate concrete showed higher tensile strength than standard concrete (HDPE-0) that may be associated with the ductility of HDPE fine and coarse aggregates [12]. It was also observed that when HDPE fine aggregate concrete samples are broken, that most HDPE particles in the concrete matrix have not been broken; instead they had peeled off from the dry concrete matrix, when the breaking stress is reached [14]. Elastic modulus of a concrete mix is mainly based on the types of aggregates used, density and the compressive strength of the concrete [14]. Modulus of elasticity of HDPE coarse aggregate concrete decreases with the increase of HDPE which may be due to reasons such as increase of volume of pores in concrete matrix, the difference in modulus of elasticity values of HDPE particles and the concrete mix and internal defects (cracks occurred around HDPE particles) [14]. 

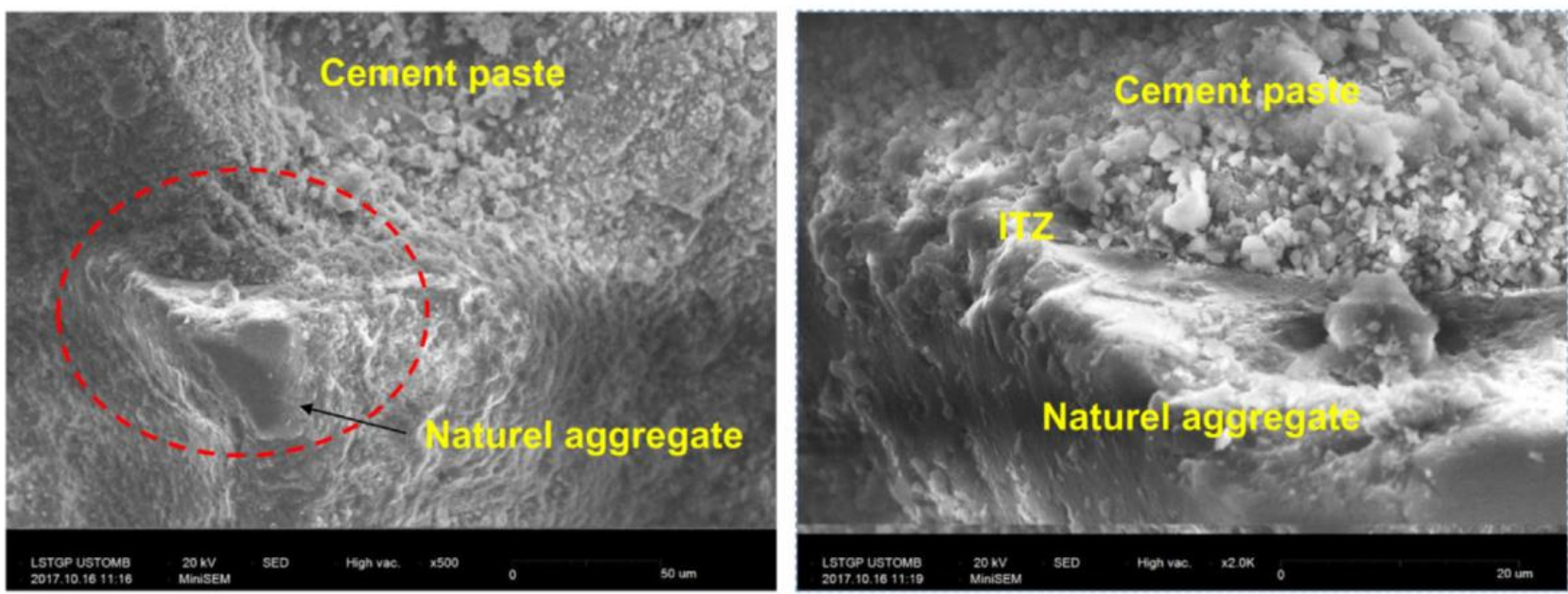

Figure 6. SEM images with weaker ITZ interfaces of HDPE-60 concrete matrix [14].
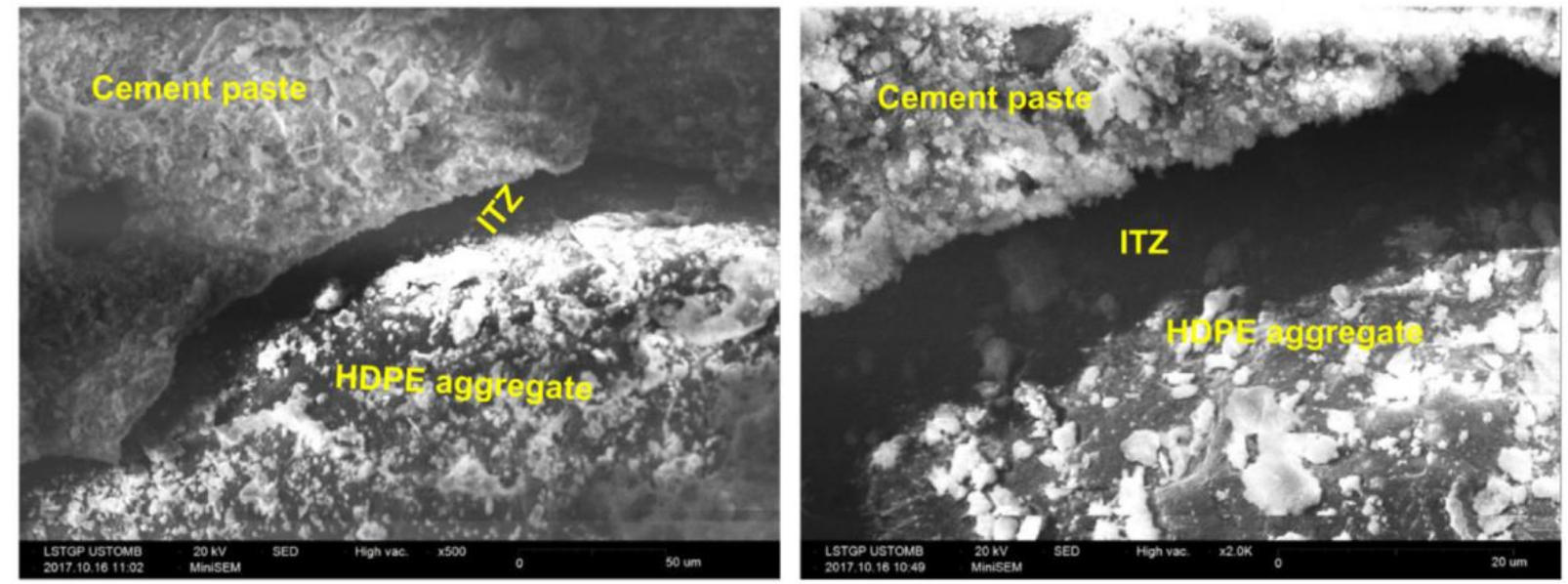

Figure 7. SEM images with stronger ITZ interfaces of standard concrete matrix (HDPE-0) [14].

Increase in water adsorption of HDPE fine aggregate concrete with the increase of HDPE percentage is mainly due to the lack of interface bonding between HDPE and the aggregates, the increase in the porosity of the concrete matrix, and the higher HDPE content which occupies the space in the concrete, which could evaporate water which leads to leaving voids thus increasing the absorption value while creating more spaces to fill up with water $[15,16]$. The velocity of waves strongly depends on the mechanical properties of the concrete and is highly influenced by the voids in the concrete. The pores created because of HDPE particles slow down the velocity of the ultrasonic wave due to the increase in the acoustic impedance. When the incident wave passes through concrete, HDPE and pores, some waves are partially reflected, and the rest are transmitted. This phenomena leads to a reduction in wave velocity with the increase of HDPE content [14]. Thermal conductivity of HDPE fine aggregate concrete has dropped with the increase of HDPE content due to the storage of a significant amount of water in the pores [14]. It was also noted that the thermal conductivity of standard concrete (HDPE-0) is higher than that of the HDPE fine aggregate concrete which may be due to HDPE having a low thermal conductivity (0.4 W.m1 K1) compared with the conductivity of natural sand [14]. When considering the chloride ion penetration test, it was observed that chloride ion penetration has reduced and lies in the favorable range of 2000-4000 coulombs with the increase of HDPE mainly due to the impervious HDPE granules which block the passage of chloride ion penetration and deterioration of the concrete [12]. Testing the concrete mixes against chemical attacks is vital 
as the reaction of chemical elements from exposure and moisture present in the concrete can result in deterioration of concrete structures. Philomina and D'Mello [18] have noted that the effect of chemicals on HDPE concrete is lesser when compared with the standard concrete matrix (HDPE-0). They have further identified that the chemical composition of HDPE coarse aggregate concrete is having the ability to resist the chemical actions and corrosion [18]. When considering the acid attack test, the reduction in compressive strength and the weight of HDPE coarse aggregate concrete with the increase of HDPE is greater in $\mathrm{H} 2 \mathrm{SO} 4$ acidic medium than the water [16]. This reduction in compressive strength and weight is due to the deposit of the gypsum which is formed following the action between the portlandite and $\mathrm{H} 2 \mathrm{SO} 4$ acid [16].

The addition of HDPE and other plastic fibers to concrete mixes have shown more ductile behavior than conventional concrete [21]. According to Poonyakan et al. [26], the slump values are dropped with the increase of HDPE, resulting in a reduction in the workability of HDPE fiber reinforced concrete. This may lead to segregate the concrete due to the restriction of the movement of fresh concrete. The reduction of workability is due to the increase of the viscosity of fiber reinforced concrete and the improvement in absorption capacity of the cement paste with the increase of surface area of HDPE fibers at high volume fractions [26]. Compressive strength of fiber reinforced concrete decreases with the increase of HDPE fibers in large volume fractions, which may be due to the hydrophobic property of HDPE which is likely to increase air voids in the concrete matrix [26]. When ductile fibers are added into HDPE fiber reinforced concrete, it will improve its tensile strength depending on several factors such as fiber toughness, fiber volume fraction, alignment, and the adhesion strength between the fibers and the cementitious matrix [26]. Larger volume fractions of HDPE often leads to clumping or balling of fibers, making them less effective in strengthening the concrete composites [26]. The use of HDPE as a reinforcement material in concrete resulted in reducing the bulk density of produced HDPE fiber reinforced concrete than that of the standard concrete (HDPE-0), which may be due to the complex network structures created by HDPE which resulted in honeycombs [26]. Thermal conductivity of HDPE fiber reinforced concrete is not only affected by HDPE fiber properties, but also small permeable voids formed in the concrete mix which can also restrain heat transfer. It was observed that more permeable voids are formed in the HDPE fiber reinforced concrete with the increase of HDPE content, which will lead to a decrease in the thermal-inducing properties or heat transfer characteristics of concrete matrix [26].

X-ray Diffract Meter (XDM) spectra analysis [31] was conducted by Aattache et al. [28] to identify the chemical interaction between the cement material and the HDPE fibers replaced. Figure 8a shows the XDM spectrum of standard concrete matrix (HDPE-0) at $20{ }^{\circ} \mathrm{C}$ which reveals that there is no chemical interaction between the cement and the HDPE and no formation of new chemical products. It also displays that a rearrangement of the crystalline structure has occurred during cement hydration, as absorption bands characterizing anhydrous clinker are replaced by the hydration particles [28]. Figure $8 \mathrm{~b}$ further illustrates the XDM spectrum of cement replaced at 6-HDPE at $20^{\circ} \mathrm{C}$. It also reveals that there is no chemical interaction between the cement and the HDPE as well as no chemical products' formation. However, it highlights the presence of high and intensive peaks of quartz, characterizing the presence of silica due to the adjuvant incorporated [28]. Similarly, the portlandite peak of standard motor without HDPE $(18,092 \mathrm{~h})$ is slightly greater than that of HDPE-6 because of the high rate of silica (90\%) relative to portlandite, and the addition of HDPE may cause a progressive decrease of portlandite in the HDPE-6 relative to standard concrete [28]. Cement and HDPE morphologies have been observed under different temperatures and it was observed that with the increase of temperature, HDPE concrete becomes less compact and deteriorates. This phenomenon is clearly marked by the existence of pores, $108 \mu \mathrm{m}$ in size at $250{ }^{\circ} \mathrm{C}$ and of $162 \mu \mathrm{m}$ at $350{ }^{\circ} \mathrm{C}$. The cracks were formed because of the absence of HDPE, letting the pores become the entry points for air [28]. Thermal conductivity of concrete where HDPE is used as a cement replacement was decreased with the increment of HDPE content due to the presence of pores distributed 
within the material in the concrete mix during the elimination of HDPE, reduction in pore appearance by nano-silicates, and as nano-particles behave as a filling agent [28].

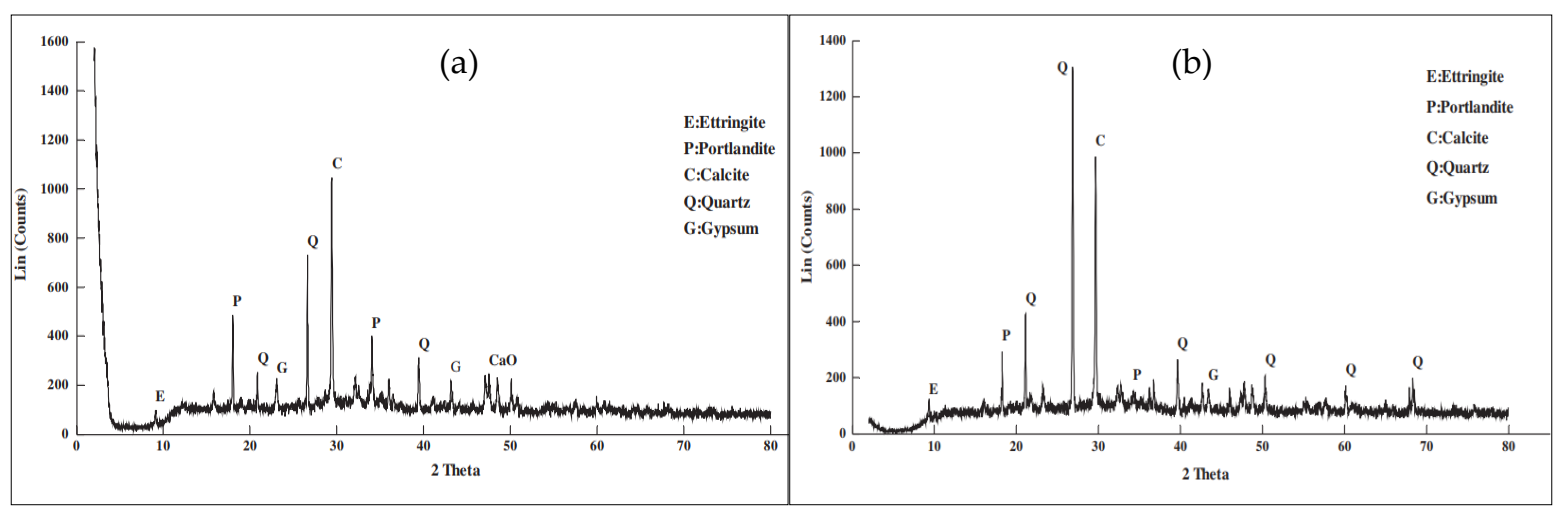

Figure 8. XDM spectrum of (a) Standard concrete Matrix (HDPE-0) and (b) Cement replaced HDPE-6 concrete matrix at $20{ }^{\circ} \mathrm{C}[29]$.

\section{Summary and Conclusions}

The mechanical and durability properties of concrete incorporated with recycled HDPE as a fine aggregate, a coarse aggregate, a fiber, and a cement binder is comprehensively reviewed. The principal conclusions drawn are listed below:

- Optimum 28-days' compressive and flexural strength of HDPE fine aggregate concrete is observed at HDPE-10 and splitting tensile strength at HDPE- 5 whereas for HDPE coarse aggregate concrete, optimum compressive and flexural strength are recorded in the range of $10 \%$ to $15 \%$ of HDPE incorporation and splitting tensile strength at HDPE-15.

- Water absorption of HDPE fine and coarse aggregate concrete is increased by $5.4 \%$ and $35 \%$ with the increase of HDPE from $0 \%$ to $15 \%$ and $20 \%$, respectively, while porosity and permeability of HDPE coarse aggregate concrete was increased by $65 \%$ and $461 \%$ with the increase of HDPE percentage from $0 \%$ to $30 \%$.

- Similarly, other durability properties of HDPE fine and coarse aggregate concrete such as lower thermal conductivity ( $25 \%$ drop) and higher resistance against chloride, sulphate and acid attacks were observed with inclusion of HDPE up to $32 \%$ more than the standard/plain concrete matrix (HDPE-0) always.

- Increasing the HDPE percentage up to $1.25 \%$ and maintaining the $\mathrm{w} / \mathrm{c}$ ratio at 0.62 reduces the workability by $80 \%$ and increases the elastic of modulus by $4.1 \%$ of HDPE fiber reinforced concrete.

- The 28-days' flexural and splitting tensile strength of HDPE fiber reinforced concrete is increased up to an optimum of 4.9 MPa (at HDPE-3) and 4.4 MPa (at HDPE-3.5) with an increase of HDPE from $0 \%$ to $6 \%$, and was higher than the standard/plain concrete matrix (HDPE-0) in all inclusion levels of HDPE.

- HDPE fiber reinforced concrete where HDPE is increased up to $1.25 \%$ display better durability properties than the standard/plain concrete matrix (HDPE-0) due to the reduction of water permeability by $39.5 \%$ and plastic shrinkage cracking by $83.6 \%$ when considering the average crack width reduction.

- Weaker bonds and lower adhesion strength between the concrete mix and HDPE aggregates are mainly due to the hydrophobic nature, smooth and glossy surface texture and the chemical inert behavior of HDPE which result in reducing both durability and mechanical performances of HDPE fine and coarse aggregate concrete with the increase of HDPE.

- When ductile fibers are added into HDPE fiber reinforced concrete, it will improve its tensile strength depending on several factors such as fiber toughness, fiber vol- 
ume fraction, alignment, and the adhesion strength between the fibers and the cementitious matrix.

\begin{abstract}
Author Contributions: Conceptualization, S.A. and C.G.; methodology \& formal analysis, S.A., C.G., and C.B.; writing-original draft preparation, S.A. and C.G.; writing-review and edit-ing, C.G., C.B., K.N., R.D. and P.M. All authors have read and agreed to the published version of the manuscript.

Funding: This research was supported by the Australian Research Council Industrial Transformation of Reclaimed Waste Resources to Engineered Materials and Solutions for a Circular Economy (IH200100010) and CRC-P on "Upcycling solutions for hazardous claddings and co-mingled waste" (CRCPEIGHT00084), which are gratefully acknowledged.
\end{abstract}

Institutional Review Board Statement: Not applicable.

Informed Consent Statement: Not applicable.

Data Availability Statement: All data are included in the manuscript

Conflicts of Interest: The authors declare that they have no conflict of interest.

\title{
References
}

1. Kaza, S.; Yao, L.; Bhada-Tata, P.; Van Woerden, F. What a Waste 2.0: A Global Snapshot of Solid Waste Management to 2050; The World Bank: Washington, DC, USA, 2018. [CrossRef]

2. Tiseo, I. Plastic Waste Worldwide-Statistics and Facts. Available online: https://www.statista.com/topics/5401/global-plasticwaste/\#dossierSummary_chapter1. (accessed on 4 September 2020).

3. Geyer, R.; Jambeck, J.; Law, K.L. Production, use, and fate of all plastics ever made. Sci. Adv. 2017, 3, 1207-1221. [CrossRef] [PubMed]

4. Andersen, L.; Wejdling, A.; Neidel, T.L. Plastic Waste-Background Report; Nordic Council of Ministers: Beau Vallon, Seychelles, 2015.

5. Lukkassen, D.; Meidell, A. Advanced Materials and Structures and Their Fabrication Processes; Narrik University College: Hin, Norway, 2003.

6. Nguyen, K.T.; Navaratnam, S.; Mendis, P.; Zhang, G.K.; Barnett, J.; Wang, H. Fire safety of composites in prefabricated buildings: From fibre reinforced polymer to textile reinforced concrete. Compos. Part B. Eng. 2020, 187, 107815. [CrossRef]

7. Gunasekara, C.; Setunge, S.; Law, D.W.; Willis, N.; Burt, T. Engineering Properties of Geopolymer Aggregate Concrete. J. Mater. Civ. Eng. 2018, 30, 04018299. [CrossRef]

8. Saikia, N.; de Brito, J. Use of plastic waste as aggregate in cement mortar and concrete preparation: A review. Constr. Build. Mater. 2012, 34, 385-401. [CrossRef]

9. Alauddin, M.; Choudhury, I.; El Baradie, M.; Hashmi, M. Plastics and their machining: A review. J. Mater. Process. Technol. 1995, 54, 40-46. [CrossRef]

10. Biswas, S. Determination of strength characteristics of concrete by partial replacement of aggregates with e waste and hdpe granules. J. Xian Univ. Archit. Technol. 2020, 12, 90-108.

11. Suganthy, P.; Chandrasekar, D. Utilization of pulverized plastic in cement concrete as fine aggregate. Int. J. Res. Eng. Technol. 2013, 2, 1015-1019.

12. Shanmugapriya, M.M. Helen Santhi. Strength and chloride permeable properties of concrete with high density polyethylene wastes. Int. J. Chem. Sci. 2017, 15, 108-116.

13. Galupino, J. Response Surface Modelling of Concrete mixed with Fly Ash and Recycled HDPE. 2019. Available online: https: //www.dlsu.edu.ph/wp-content/uploads/pdf/conferences/research-congress-proceedings/2019/see-I-003.pdf (accessed on 1 June 2021).

14. Badache, A.; Benosman, A.S.; Senhadji, Y;; Mouli, M. Thermo-physical and mechanical characteristics of sand-based lightweight composite mortars with recycled high-density polyethylene (HDPE). Constr. Build. Mater. 2018, 163, 40-52. [CrossRef]

15. Chidiac, S.; Mihaljevic, S. Performance of dry cast concrete blocks containing waste glass powder or polyethylene aggregates. Cem. Concr. Compos. 2011, 33, 855-863. [CrossRef]

16. Kodua, J. Influence of recycled waste high density polyethylene plastic aggregate on the physico-chemical and mechanical properties of concrete. Int. J. Sci. Eng. Sci. 2018, 2, 22-28.

17. Al Bakri, A.M. Investigation of HDPE plastic waste aggregate on the properties of concrete. J. Asian Sci. Res. 2011, 1, 340-345.

18. Philomina, S.; D'Mello, M. An Experimental Investigation to Produce a Cost Effective Concrete by Partial Replacement of Coarse Aggregate with High Density Polyethylene (HDPE) Waste And Cement with Alccofine. Int. Res. J. Eng. Technol. 2017, 4(7), 2712-2717.

19. Rahim, N.L.; Sallehuddin, S.; Ibrahim, N.M.; Amat, R.C.; Ab Jalil, M.F. Use of Plastic Waste (High Density Polyethylene) in Concrete Mixture as Aggregate Replacement. Adv. Mater. Res. 2013, 701, 265-269. [CrossRef] 
20. Lopez, N.; Collado, E.; Diacos, L.A.; Morente, H.D. Evaluation of Pervious Concrete Utilizing Recycled HDPE as Partial Replacement of Coarse Aggregate with Acrylic as Additive. In Proceedings of the MATEC Web of Conferences, EDP Sciences, Yogyakarta, Indonesia, 5-7 September 2018.

21. Habib, M.Z.; Alom, M.M. and Hoque, M.M. Concrete production using recycled waste plastic as aggregate. J. Civ. Eng. IEB 2017, $45,11-17$.

22. Zainal, S.H.; Ali, S. Effect of Fly Ash and HDPE on Concrete Strength. Politeknik \& Kolej Komuniti. J. Eng. Technol. 2018, 3, 81-89.

23. Rahman, M.; Islam, A.; Ahmed, M.; Salam, A. Recycled Polymer Materials as Aggregates for Concrete and Blocks. J. Chem. Eng. 2013, 27, 53-57. [CrossRef]

24. Pešić, N.; Živanović, S.; Garcia, R.; Papastergiou, P. Mechanical properties of concrete reinforced with recycled HDPE plastic fibres. Constr. Build. Mater. 2016, 115, 362-370. [CrossRef]

25. Tahmasebinia, F.; Niemelä, M.; Sepasgozar, S.M.E.; Lai, T.Y.; Su, W.; Reddy, K.R.; Shirowzhan, S.; Sepasgozar, S.; Marroquin, F.A. Three-Dimensional Printing Using Recycled High-Density Polyethylene: Technological Challenges and Future Directions for Construction. Buildings 2018, 8, 165. [CrossRef]

26. Poonyakan, A.; Rachakornkij, M.; Wecharatana, M.; Smittakorn, W. Potential Use of Plastic Wastes for Low Thermal Conductivity Concrete. Materials. 2018, 11, 1938. [CrossRef] [PubMed]

27. Malagavelli, V.; Patura, N.R. Strength characteristics of concrete using solid waste an experimental investigation. Int. J. Earth Sci. Eng. 2011, 4.

28. Aattache, A.; Mahi, A.; Soltani, R.; Mouli, M.; Benosman, A.S. Experimental study on thermo-mechanical properties of Polymer Modified Mortar. Mater. Des. 2013, 52, 459-469. [CrossRef]

29. Naik, T.; Singh, S.; Huber, C.; Brodersen, B. Use of post-consumer waste plastics in cement-based composites. Cem. Concr. Res. 1996, 26, 1489-1492. [CrossRef]

30. Mohammed, H.; Sadique, M.; Shaw, A.; Bras, A. The influence of incorporating plastic within concrete and the potential use of microwave curing; A review. J. Build. Eng. 2020, 32, 101824. [CrossRef]

31. Gunasekara, C.; Law, D.W.; Setunge, S.; Burgar, I.; Brkljaca, R. Effect of Element Distribution on Strength in Fly Ash Geopolymers. ACI Mater. J. 2017, 114, 795-808. [CrossRef] 